\title{
Combating autophagy is a strategy to increase cytotoxic effects of novel ALK inhibitor entrectinib in neuroblastoma cells
}

\author{
Sanja Aveic ${ }^{1}$, Marcella Pantile ${ }^{1}$, Anke Seydel ${ }^{1}$, Maria Rosaria Espositoํㅜ ${ }^{1}$ Carlo Zanon ${ }^{1}$, \\ Gary Lí ${ }^{2}$, Gian Paolo Tonini ${ }^{1}$ \\ ${ }^{1}$ Neuroblastoma Laboratory, Pediatric Research Institute, Città della Speranza, Padua, Italy \\ ${ }^{2}$ Ignyta, Inc., San Diego, California, USA \\ Correspondence to: Sanja Aveic, e-mail: s.aveic@irpcds.org \\ Keywords: neuroblastoma, autophagy, ALK inhibitors; drug combination, entrectinib \\ Received: July 21, $2015 \quad$ Accepted: December 22, $2015 \quad$ Published: December 28, 2015
}

\section{ABSTRACT}

Neuroblastoma (NB) is a threatening childhood malignancy. Its prognosis is affected by several morphological, and biological characteristics, including the constitutive expression of ALK tyrosine kinase. In this study we examined the therapeutic potential of a novel ALK inhibitor, entrectinib, in obliterating NB tumor cells.

Entrectinib showed the growth-inhibitory effects on NB cells with a $50 \%$ inhibitory concentration range of 0.03-5 $\mu \mathrm{M}$. In the ALK-dependent cells, entrectinib mediated G1-arrest, which was associated with modified expression of multiple cell-cycle regulators. Down-regulation of $\mathrm{Ki}-67$, and attenuated phosphorylation of ERK1/2, and STAT3, correlated with observed antiproliferative capacity of entrectinib. Initial cytostatic activity of entrectinib was followed by concentration-dependent apoptotic cell death, and Caspase-3 activation. However, we delineated a reduced sensitivity of $A L K$ mutated NB cells to entrectinib, and demonstrated strong activation of autophagy in SH-SY5YF1174L NB cell line. Abrogation of autophagy by chloroquine increased significantly the toxicity of entrectinib, as confirmed by enhanced death rate, and PARP protein cleavage in SH-SY5YF1174L cells.

In aggregate, our data show that entrectinib inhibits proliferation, and induces G1-arrest, and apoptosis in NB cells. We propose entrectinib for further consideration in treatment of $\mathrm{NB}$, and recommend pharmacological inhibition of autophagy to be explored for a combined therapeutic approach in NB patients that might develop resistance to entrectinib.

\section{INTRODUCTION}

Neuroblastoma (NB) is one of the most common cancers in children under 1 year of age, and accounts for $15 \%$ of all pediatric cancer mortality [1]. While some NBs respond strongly to treatment or even regress spontaneously without cure, there are still a considerable number of NB cases in which current therapy is ineffective [2]. Some clinical, and molecular biological factors correlate with outcome of NB patients, and are defined as prognostic markers of this disease [3]. $M Y C N$ gene amplification has been observed in about $20 \%$ of all NB cases, and represents one of the strongest markers associated with the aggressiveness of the disease [4]. Increased expression of other genes, such as TrkA, and caspase-1/-3/-8, were described to correlate with favorable prognosis, whereas increased expression of $\operatorname{Trk} B$, and Survivin, were associates with unfavorable outcome [57]. More recently, the $A L K$ (anaplastic lymphoma kinase) gene has been found mutated in about $8 \%$ of sporadic NB, and has been associated with rapid disease progression [6-8].

$A L K$ gene encodes for a cell surface neural receptor tyrosine kinase (RTK) which is dominantly expressed in developing embryonic, and neonatal brain [9]. The $A L K$ mutations are shown to give the proliferative advantages to the cells in which they occur [10], and the constitutive activation of $A L K$ gene has been found to give a particular negative impact over prognosis of NB [11]. The $A L K^{\mathrm{F} 1174 \mathrm{~L}}$, and $A L K^{\mathrm{R} 1275 \mathrm{Q}}$ are the most frequent mutations found in sporadic NBs, leading to a single amino acid substitution in the tyrosine kinase domain (TKD) of ALK receptor 
[12]. Similarly to other RTK, these mutations cause a constitutive activation of ALK receptor, and downstream ALK-dependent regulatory pathways, giving a crucial impact over NB oncogenesis. Taken together, these findings introduced the possibility of targeting ALK protein in NB patients. During recent years, several compounds have been proposed for the treatment of patients with deregulated ALK protein, showing a diverse efficiency, and specificity $[12,13]$. Nevertheless, the obstacle related to the use of ALK inhibitors in NB therapy remains their low efficiency in impairment of $A L K$-mutated NBs' growth. This problem is usually correlated with the acquired resistance of tumor cells, which prevents the successful treatment of NB patients $[14,15]$. Hence, it becomes necessary to screen for a more successful therapeutic approaches, to overcome current therapy restrictions.

Here, we tested a novel ALK inhibitor entrectinib (RXDX-101) (Ignyta, San Diego) for its capacity to abrogate growth of NB cell lines with different status of $A L K$ gene (wild type, mutated or amplified) in vitro. We showed that entrectinib was able to impair $A L K$-amplified $\left(A L K^{a m p}\right)$ cells' growth, and proliferation, whereas its activity was less effective in NB cell lines bearing $A L K$ mutation $\left(A L K^{\mathrm{F} 1174 \mathrm{~L}}\right.$, and $\left.A L K^{\mathrm{R} 1275 \mathrm{Q}}\right)$, or wild type $\left(A L K^{w t}\right)$ gene. We investigated for a mechanism possibly involved in low efficiency of entrectinib in $A L K$-mutated cells, and observed that autophagy induction after entrectinib addition was responsible for drug resistance. Chemical inhibition of autophagy increased significantly the efficiency of entrectinib in $A L K$-mutated cells, suggesting a combined therapy as a promising approach in patients with $A L K^{\mathrm{F} 1174 \mathrm{~L}}$ or $A L K^{\mathrm{R} 1275 \mathrm{Q}}$ positive tumors.

\section{RESULTS}

\section{Entrectinib blocks proliferation of NB cells}

To evaluate the concentration range activity of entrectinib, we treated NB1 $1^{\mathrm{amp}}, \mathrm{NB} 3^{\mathrm{R} 1275 \mathrm{Q}}$, SHSY5Y $\mathrm{Y}^{\mathrm{F} 1174 \mathrm{~L}}$, and IMR32 ${ }^{\text {wt }}$ cells with increasing concentrations of entrectinib. The cell viability was checked after $24 \mathrm{~h}, 48 \mathrm{~h}$, and $72 \mathrm{~h}$, by MTT assay. The inhibitory concentration of $50 \%\left(\mathrm{IC}_{50}\right)$ was calculated for each time point (Supplementary Table S1). Dose dependent cell viability reduction was observed in all cell lines. However, the cell viability was highly depressed in NB1 $1^{\text {amp }}$ cells, which was extremely sensitive to entrectinib treatment $\left(48 \mathrm{~h} \mathrm{IC}_{50}=0.035 \pm 0.009 \mu \mathrm{M}\right)$. Sensitivity of other cell lines (NB3 ${ }^{\mathrm{R} 1275 \mathrm{Q}}, \mathrm{SH}-\mathrm{SY} 5 \mathrm{Y}^{\mathrm{F} 1174 \mathrm{~L}}$, IMR32 $^{\text {wt }}$ ) was also detected although it was lower with respect to NB1 cells $\left(48 \mathrm{~h} \mathrm{IC}_{50}\right.$; $\mathrm{NB} 3=2.24 \pm 0.89 \mu \mathrm{M}$; SH$\mathrm{SY} 5 \mathrm{Y}=3.32 \pm 0.90 \mu \mathrm{M}, \mathrm{IMR} 32=3.29 \pm 0.35 \mu \mathrm{M}$; Figure 1A). Subsequently, we looked whether entrectinib induces cell morphology changes. We observed dramatic cell shape changes since the cells became smaller in size. Moreover, NB cells greatly reduced the capacity to become confluent (Supplementary Figure S1). A capacity of entrectinib to reduce NB cells' proliferation was validated in following. Concomitantly, after $24 \mathrm{~h}$ of treatment, the cells showed a significant proliferative block that was directly proportional to the concentration of entrectinib used, and was maintained until $72 \mathrm{~h}$ of treatment (Figure 1B; Supplementary Table S2).

Decreased proliferative capacity of entrectinib treated NB cells was confirmed by evaluating Ki-67 nuclear antigen, an important marker of cell proliferation [16], by Real Time quantitative PCR (qRT-PCR). We confirmed a significant decreasing of $\mathrm{Ki}-67 \mathrm{mRNA} 24 \mathrm{~h}$ after treatment with entrectinib, particularly in NB1, NB3, and SH-SY5Y cell lines, and in a lesser extent in IMR32 cells (DMSO control: RQ $=1$; RQ of treatments: $\mathrm{NB} 1=0.34 \pm 0.06$, $p=0.0005$; NB3 $=0.62 \pm 0.14, p=0.05$; SH-SY5Y $=$ $0.52 \pm 0.08, p=0.006$; IMR32 $=0.73 \pm 0.05, p=0.004$; $n=3$; Figure 1C). These results have been confirmed by immunocytochemistry, demonstrating the increased fraction of Ki-67 negative entrectinib-treated cells particularly in NB1 cell line, and less marked expressional changes of Ki67 protein in IMR32 cells (Supplementary Figure S2).

\section{Entrectinib induces block in G1-phase of cell-cycle}

Observed proliferative reduction of NB cells was caused in part by cell-cycle inhibition, as confirmed by propidium iodide staining analysis. The cellcycle distribution in NB1 cells, treated with a single concentration of entrectinib $(0.08 \mu \mathrm{M})$, demonstrated a significant accumulation in G1-phase after $24 \mathrm{~h}$, with respect to control $(\mathrm{G} 1,24 \mathrm{~h}$ : DMSO $=55.4 \pm 3.0 \%$; entrectinib $=83.0 \pm 4.3 \% ; n=3, p=0.006$; Figure 2A). Additionally, a decrease of S-phase was confirmed $(\mathrm{S}, 24 \mathrm{~h}: \mathrm{DMSO}=38.6 \pm 2.8 \%$; entrectinib $=6.5 \pm 4.4$ $\% ; n=3, p=0.004$; Figure $2 \mathrm{~A}$ ). For the remaining 3 cell lines, a tendency of G1-arrest was observed even though a statistical significance was not reached for the concentration of entrectinib used $(2.5 \mu \mathrm{M}$; Supplementary Figure S3A, S3B and S3C). Moreover, we examined the association between entrectinib-induced G1-arrest, and alteration of cell-cycle regulatory genes. We analyzed the expression contents of $p 21, p 27$, Cyclin A1, Cyclin D1, $C y c l i n E 1, R B 1$, and $E 2 F 1$ genes, which are well-known cell-cycle regulators. Expression levels of $R B 1, E 2 F 1$, Cyclin D1, Cyclin E1, and Cyclin A1, were significantly reduced in entrectinib treated NB1 cells, whereas the contents of $p 21$, and $p 27$ were markedly increased (Figure 2B, and Supplementary Table S3) when compared to control samples (DMSO: RQ = 1), mirroring the changes in cell-cycle distribution observed previously. The similar changes in genes' expression were found for the remaining NB cell lines (Supplementary Figure S3A', S3B' and $\left.\mathrm{S} 3 \mathrm{C}^{\prime}\right)$. A block of NB1 cells in G1-phase has been confirmed by Western blot analysis as well, showing a particular accumulation of $\mathrm{p} 21$ protein $24 \mathrm{~h}$ post-treatment with entrectinib (Figure 2C). Oppositely, levels of Cyclin $\mathrm{A} 1$, and E1 were down-regulated. 
A)
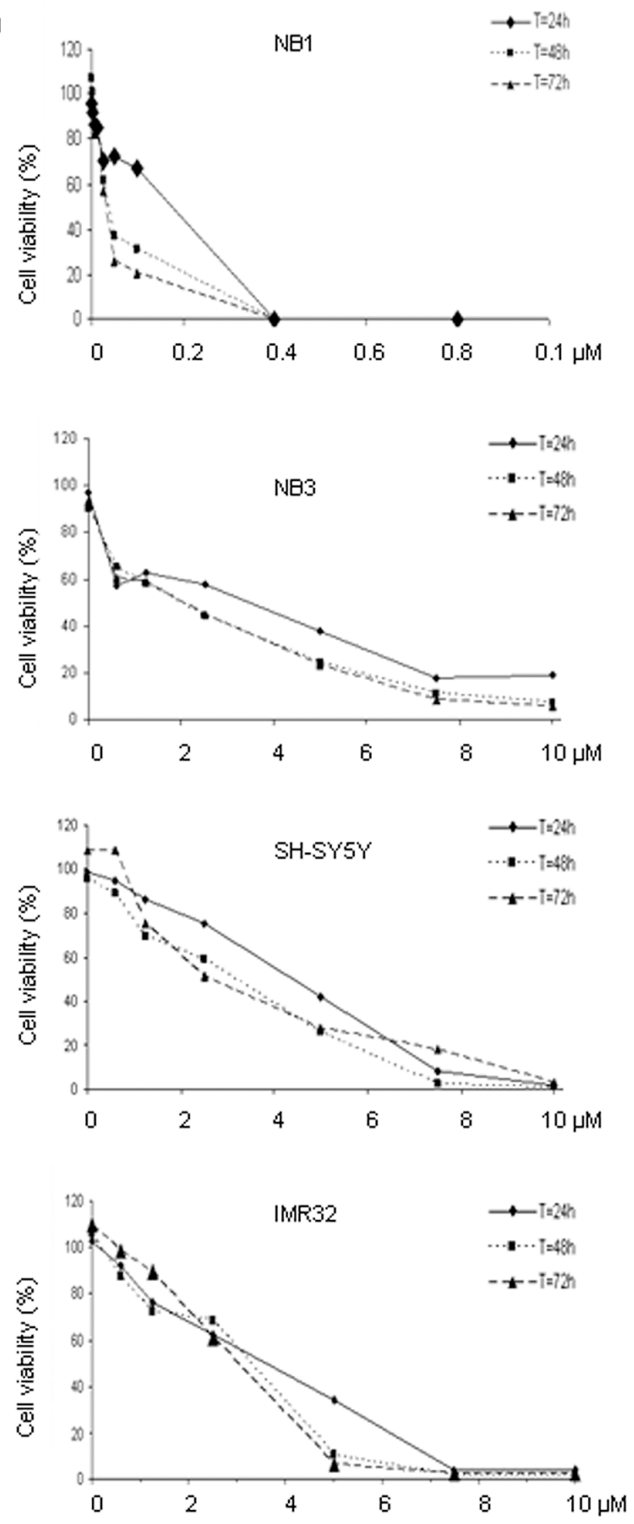

C)

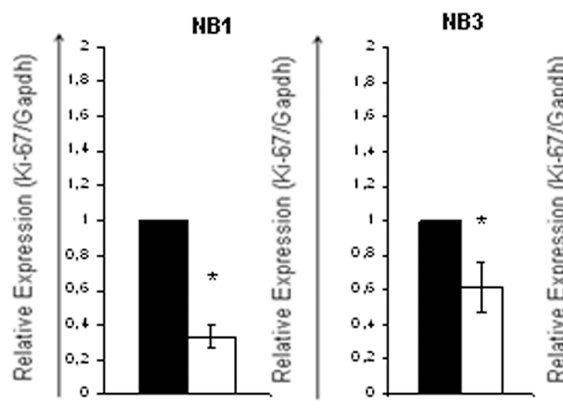

B)
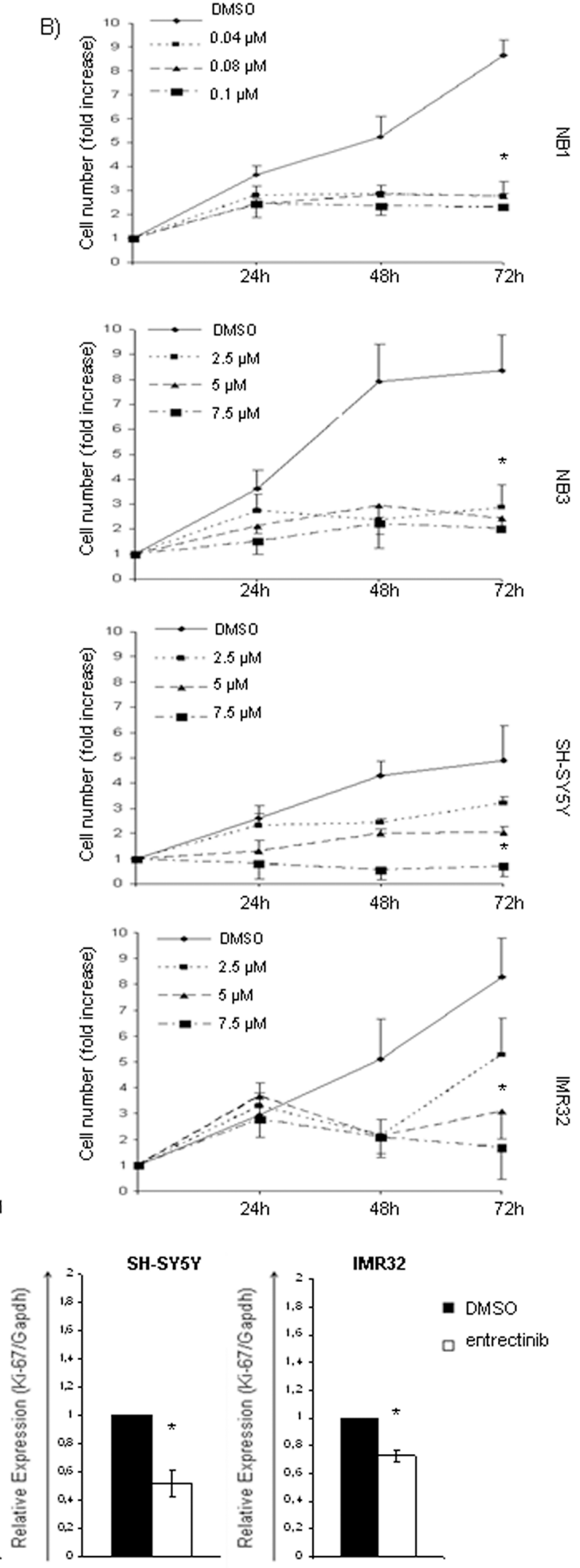

Figure 1: Inhibition of cell viability, and growth after entrectinib treatment. A. NB cells were treated with increasing concentrations of entrectinib for $24 \mathrm{~h}, 48 \mathrm{~h}$ and $72 \mathrm{~h}$, and $\mathrm{IC}_{50}$ has been calculated for each cell line (NB1, NB3, SH-SY5Y and IMR32) for three time points. Concentrations used $(\mu \mathrm{M})$ are indicated on X-axis. B. Trypan blue exclusion assay has been done to count the cell number in presence of three different concentration of entrectinib $(2.5 ; 5 ; 7.5 \mu \mathrm{M})$. Data represent fold change of cell number calculated with respect to the number of cells present in the moment of administration of entrectinib, and expressed as mean \pm SEM of 3 independent experiments. Time points are indicated on X-axis. C. Cell proliferation was measured by the means of Ki-67 mRNA expression $24 \mathrm{~h}$ after addition of entrectinib (NB1 $=0.08 \mu \mathrm{M}$; NB3, SH-SY5Y, IMR32 $=2 \mu \mathrm{M})$. Results were presented as a relative expression calculated with respect to DMSO control $(\mathrm{RQ}=1)$. Significant down-regulation of Ki-67 mRNA levels was evidenced for all cell lines. Single experiments were done in triplicates, and results presented for 3 separated treatments as mean \pm SEM. Results were considered significant for $* \mathrm{p} \leq 0.05$. 
A)

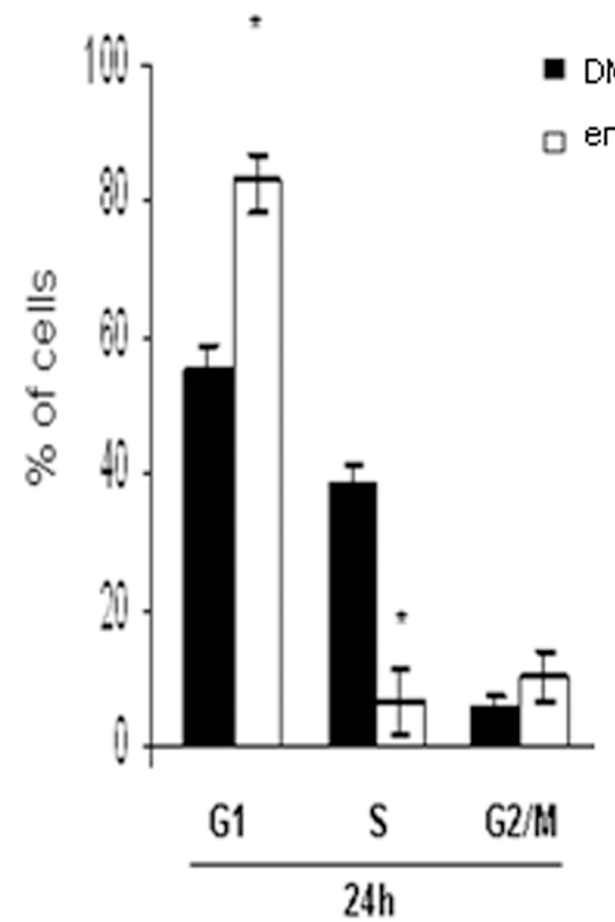

B)

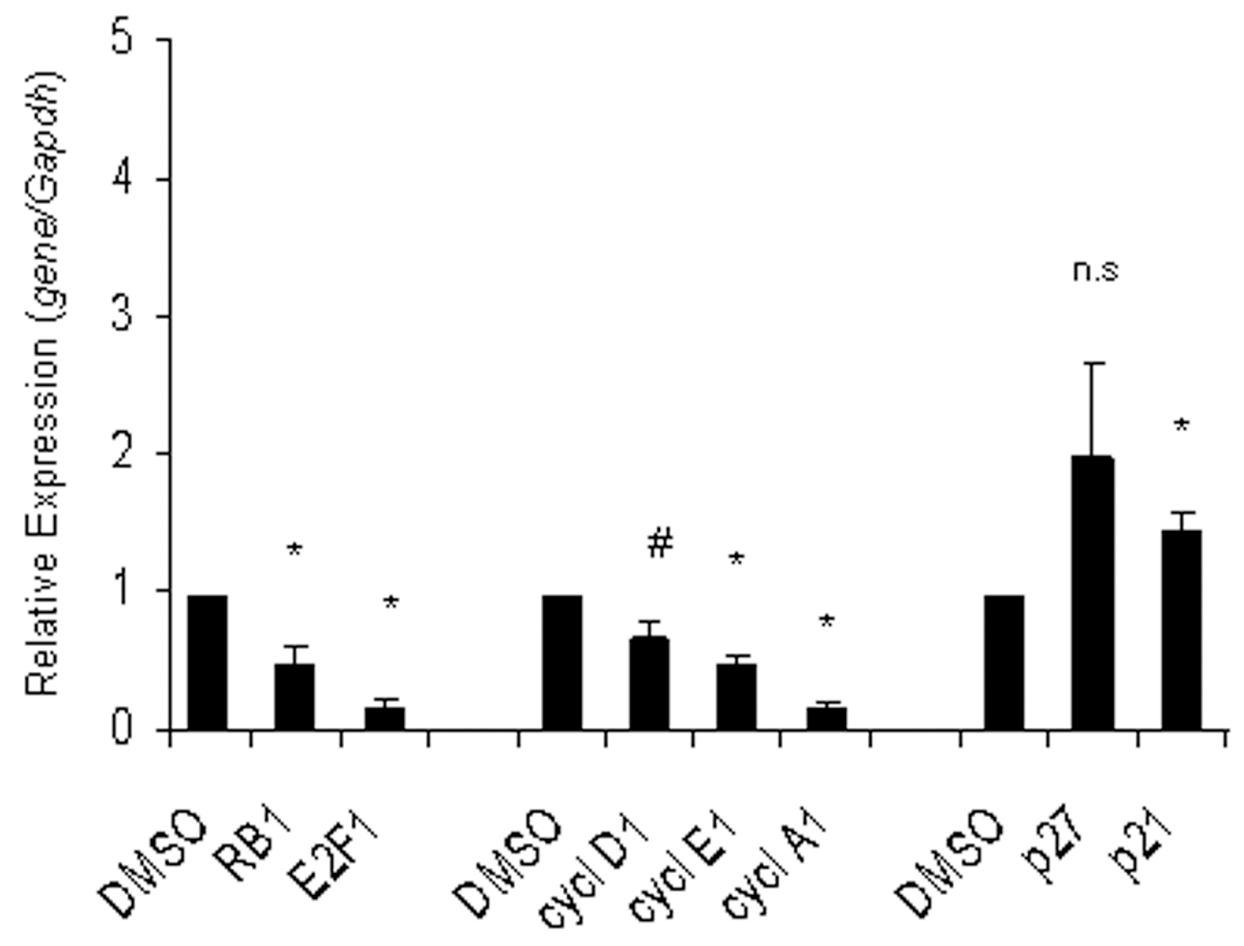

Figure 2: Entrectinib modifies cell-cycle profile. A. Cell-cycle profile was evaluated by flow cytometry. Percentage of cells in each phase of cell-cycle is presented. An important accumulation of the NB1 cells in G1-phase was confirmed 24h post-treatment. B. qRTPCR was performed for the evaluation of mRNA levels of the main cell-cycle regulators $p 21, p 27, C y c l i n A 1, D 1, E 1, p R B 1$, and E2F1, after treatment with entrectinib $(0.08 \mu \mathrm{M})$. Data were normalized for Gapdh internal control, and calculated with respect to the relative expression determined for DMSO control samples. Results were considered significant for $\mathrm{p} \leq 0.05$, and indicated with an asterisk $(*)$. $\# p=0.06$. C. Expression of cell cycle regulatory proteins (p21, p27, Cyclin A1, and Cyclin E1) was validated by Western Blot 24h after treatment with entrectinib. Gapdh was used as a control of proper protein loading. Numbers indicate concentration of entrectinib (e; $\mu \mathrm{M})$ used. D = DMSO. 


\section{Addition of entrectinib decreases the clonogenic capacity of NB cells}

We seeded NB cells in methylcellulose in addition of entrectinib to investigate the possibility of entrectinib to impair NB cells to form colonies, and let them to proliferate for 14 days (Figure 3A, left panel). The entrectinib gave rise to significantly fewer, and smaller colonies with respect to control cells (colony number $\mathrm{NB} 1: \mathrm{DMSO}=803.8 \pm 29.0$; entrectinib $=548.4 \pm$ $40.0 ; n=3 ; p=0.001 ; \mathrm{NB} 3: \mathrm{DMSO}=522.7 \pm 35.0$; entrectinib $=348.7 \pm 10.3 ; p=0.006 ; n=3$; SH-SY5Y: $\mathrm{DMSO}=727.0 \pm 65.5$; entrectinib $=437 \pm 70.9 ; n=3$; $p=0.04$; IMR32: DMSO $=648.5 \pm 19.3$; entrectinib $=$ $541.5 \pm 47.0 ; n=3 ; p=0.08$; Figure $3 \mathrm{~A}$, right panel) in all cell lines tested. Together, these results indicated that entrectinib had the capacity to inhibit NB cells to form the colonies.

\section{Entrectinib reduces motility of NB cells}

The time-lapse microscopy of NB cells after treatment with entrectinib revealed an inhibition of the motility of NB1, NB3, SH-SY5Y, and IMR32 cells upon entrectinib treatment. In the scratch assay, DMSO control cells were able to migrate into the scratch area, whereas treatment with entrectinib prevented wound closure. The scratch area (expressed as percentage of total area; Figure 3B, 3C, 3D and 3E, left images) significantly decreased for the control cells, whereas it remained largely uncovered in the presence of entrectinib (Figure $3 \mathrm{~B}, 3 \mathrm{C}, 3 \mathrm{D}$ and $3 \mathrm{E}$, right graph bars). We also observed differences in the velocity of treated cells to repopulate the scratch zone compared to controls. In particular, a complete closure was reached after $48 \mathrm{~h}$ for IMR32, $72 \mathrm{~h}$ for SH-SY5Y, and NB3, and after 96h for NB1 (data not shown). Our results clearly demonstrated the strong antimigratory effects of entrectinib on NB cells with different $A L K$ gene status.

\section{Entrectinib triggers cell death in NB cell lines}

To assess the possible induction of apoptosis, we treated NB cells with increasing concentrations of entrectinib. A significant increase in Caspase-3 activation was found for NB1 cell line, and in comparable extent for NB3, SH-SY5Y, and IMR32 cells (Figure 4A; Supplementary Table S4; $n=3 ; \mathrm{p}<0.05$ ). A dosage-dependent increase of dying cells was also observed by TUNEL assay (Figure 4B; Supplementary Table S5; $n=3 ; \mathrm{p}<0.05)$. At the protein level, cell death induction was confirmed by studying the expression of the early marker of apoptosis poly (ADP-ribose) polymerase (PARP), which was fragmented proteolytically by Caspase-3. An evident cleavage of PARP protein occurred due to entrectinib activity as shown in Figure
4C. Collectively, these results imply for entrectinib to be a potent inhibitor of NB cells growth, which is hampered by cell-cycle blocking, and inducted apoptosis. Other hallmarks of apoptosis, including mitochondrial membrane depolarization, and generation of reactive oxygen species, were not stimulated after use of $\mathrm{IC}_{50}$ dose of entrectinib (data not shown).

\section{Entrectinib blocks ALK-dependent signaling pathway}

The observed results prompted us to evaluate for the possible changes in ALK-downstream signaling pathway after addition of entrectinib. Abrogation of ALK function by adding entrectinib $\left(\mathrm{IC}_{50}\right.$ or increasing concentrations), led to a decreased expression of pERK1/2, and pSTAT3 proteins, two principal regulators of cell proliferation, in concentration, and time dependent manner (Figure 5A and 5B). Similar effects were seen for all NB cell lines tested, supporting the proliferative advantages of the NB cells with deregulated ALK function.

\section{Autophagy induction in SH-SY5Y cell line explains the low entrectinib efficiency}

$A L K^{F 1174 L}$ is considered one of the most aggressive $A L K$ mutations in $\mathrm{NB}$, and shows high transforming potential [17]. In view of the poorer efficiency of entrectinib to induce cell death in ALK mutated NB cells, particularly SH-SY5YF1174L, we speculated that some protective mechanism could be activated, contributing to the observed scenario. Autophagy represents the most common adaptive cellular response in cancer that can enhance the tumor cell survival during treatments [18]. One of the most specific indicators of autophagosome formation, and hence autophagy activation, is a microtubule associated protein 1 light chain 3 (LC3) $[19,20]$. At first, we checked how the levels of LC3-I, and LC3-II changed after addition of entrectinib. The expression of LC3-II protein was significantly induced after treatment with entrectinib for 48h (Figure 6A, upper lane), and was more evident with increase of entrectinib concentration (24h; Figure 6A, lower lane). This event was particularly marked in SH-SY5Y cells, and was confirmed by calculating the LC3-II/LC3-I ratio, demonstrating a clear prevalence of LC3-II levels in treated samples with respect to DMSO controls (LC3-II/LC3-I ratio: DMSO = 1 Arbitrary Units; entrectinib $5 \mu \mathrm{M}=5.4 \mathrm{AU}$; entrectinib $7.5 \mu \mathrm{M}=5.6 \mathrm{AU}$; Figure 6A, lower lane). Moreover, our results revealed the degradation of autophagic marker p62/SQSTM1 (Figure 6B) [21]. Interestingly, Beclin-1 levels, as an apical regulator of autophagy, did not increase significantly after treatment with diverse entrectinib concentrations, implying that the mechanism of autophagy activation in SH-SY5Y was likely independent of Beclin-1, as reported in other studies as well [22]. 
A)

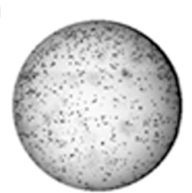

DMSO

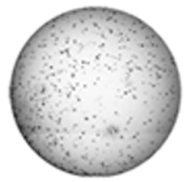

entrectinib

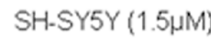

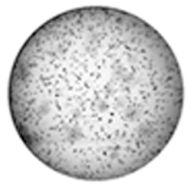

DMSO

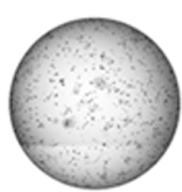

entrectinib

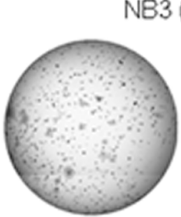

DWSO
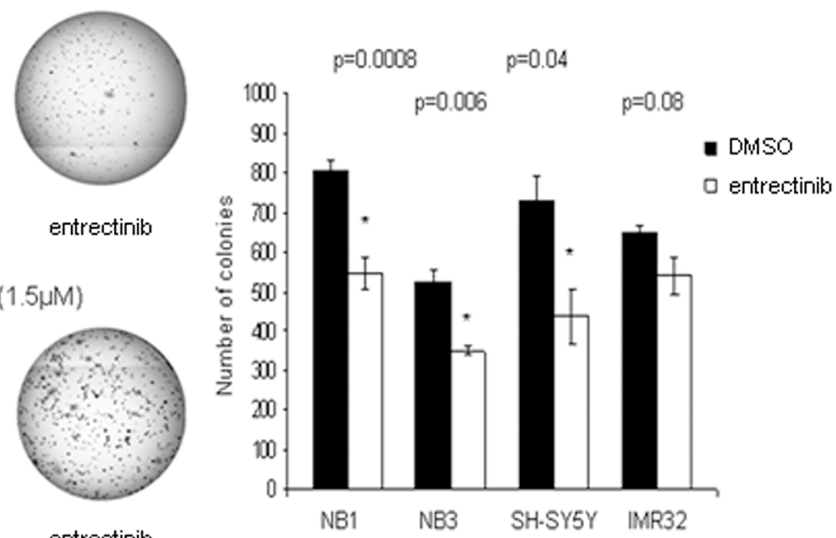

B)

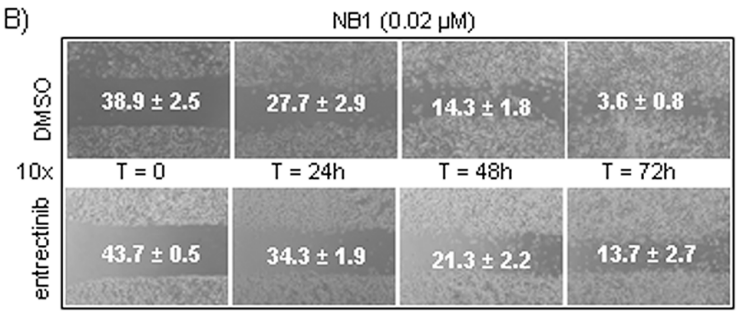

C)

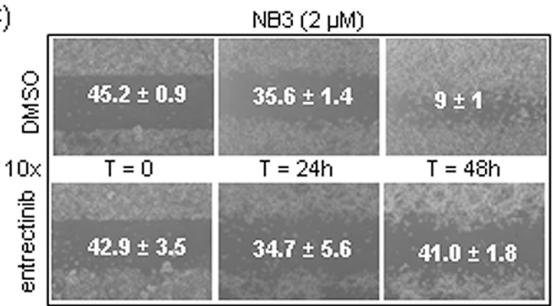

D)

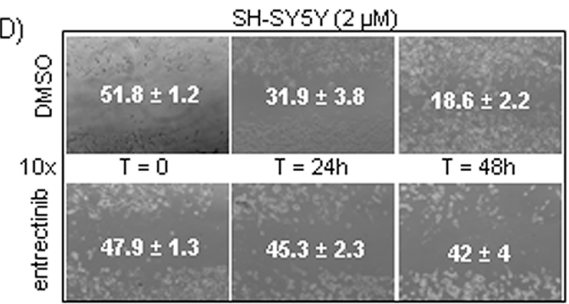

E)

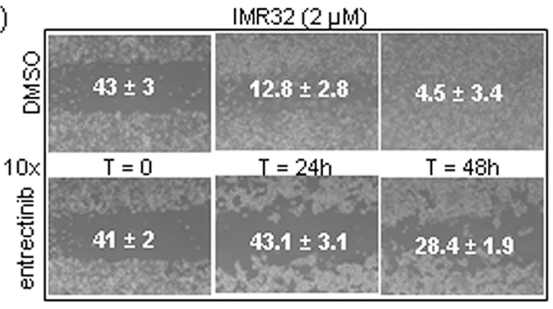

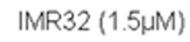

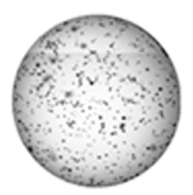

entrectinib
N81 NB3 SH.SY5Y IMR32
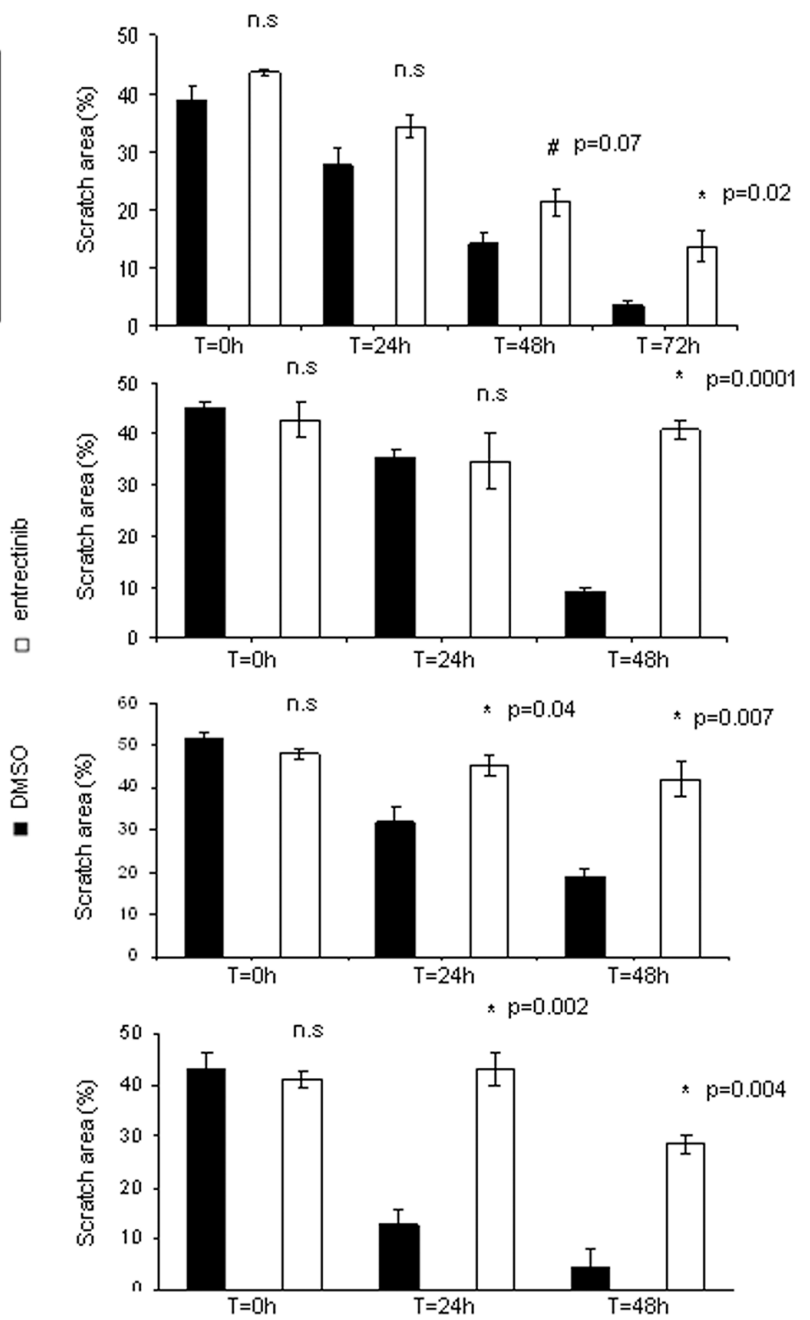

Figure 3: Entrectinib impairs NB cell clonogenic competence, and motility. A. Representative images of clonogenic assays were shown for each cell line (left side). Cells were analyzed for the foci formation during the course of 14 days in the presence of either entrectinib or DMSO control vehicle. The figure shows the capacity of entrectinib to deteriorate the colony-forming cell. The number of colonies was counted by ImageJ software after coloration with MTT, and results shown as mean \pm SEM (at right) of three independent experiments. Results were considered significant for ${ }^{*} \mathrm{p}<0.05$. Numbers within the brackets indicate the $\mu \mathrm{M}$ of entrectinib used in the experiment. B-E. Time-lapse microscopy reveals an inhibition of the motility of neuroblastoma cells upon entrectinib treatment (left side). For the wound healing assay, NB cells were treated with vehicle (DMSO control) and B) $0.02 \mu \mathrm{M}$ (NB1) or C) $2 \mu \mathrm{M}$ (NB3, SH-SY5Y, and IMR32) entrectinib, and monitored for 48-72h., The results are presented for each image (right side) as mean \pm SEM of three separate experiments, and *p-value considered significant when $\leq 0.05$. n.s.: not-significant; \# - close to significance. 
A)

A)

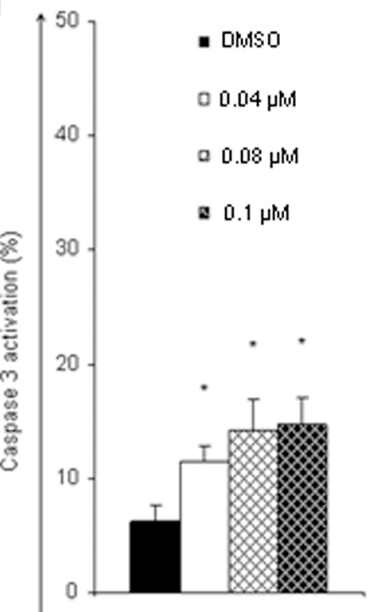

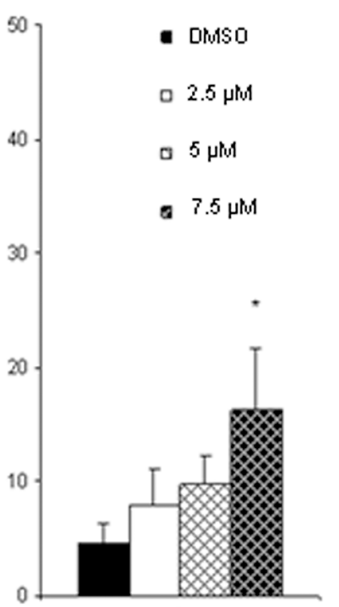
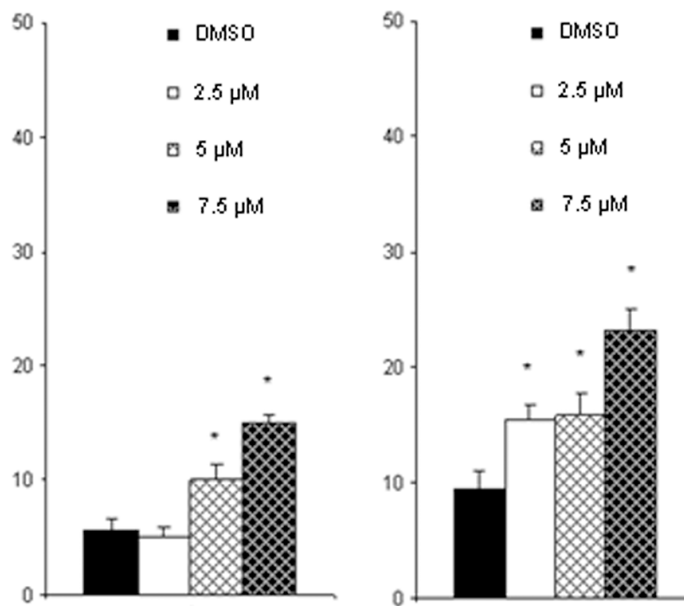

B)

NB1

NB3

SH-SY5Y

IHAR32
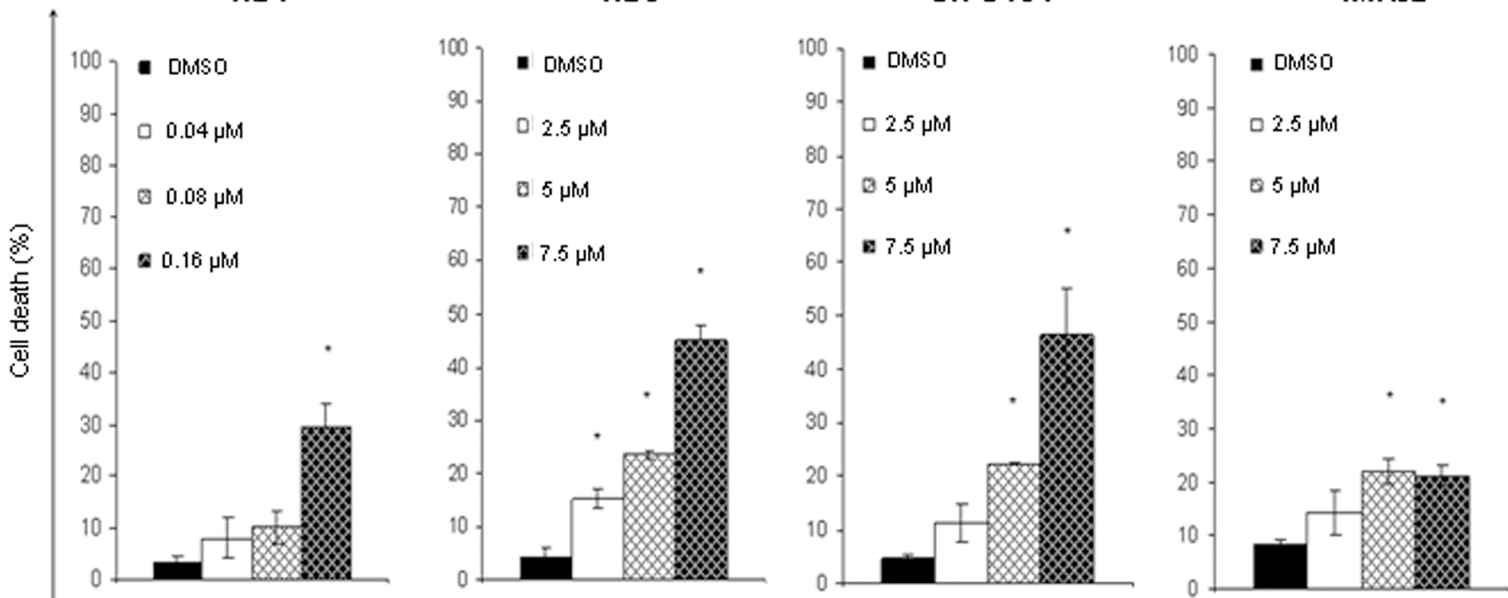

Treatment with increasing concentration of entrectinib

C)

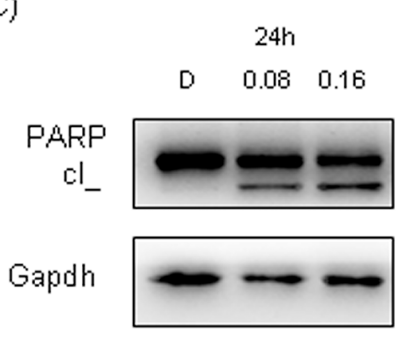

NB1

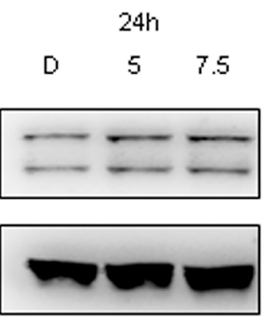

NB3

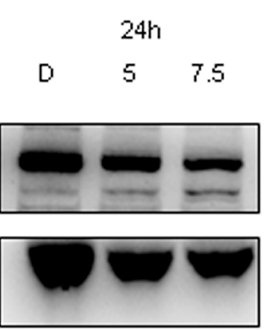

SH-SY5Y

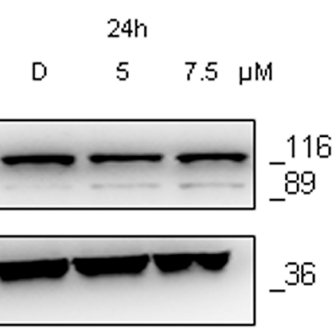

IMIR32

Figure 4: Entrectinib stimulates cell death in NB cell lines. A. The capability of entrectinib to induce Caspase-3 dependent death of NB cells was assessed applying flow cytometry technique. An increase in Caspase-3 activation was detected in different extents for diverse cell types $24 \mathrm{~h}$ after treatment with increasing concentration of entrectinib. NB1 ${ }^{\text {amp }}$ was particularly sensitive to entrectinib, whereas SH-SY5Y F1174L showed weaker sensitivity to the compound. B. Percentage of dead cells was measured by TUNEL assay, applying flow cytometry technique. The potential of entrectinib to impair cell viability was confirmed for all cell lines, for different concentration of entrectinib. The effects of entrectinib, and DMSO treated control samples are presented. Results were considered significant for *p $\leq 0.05$. C. Activation of PARP protein, as a hallmark for death induction, was seen by Western blot. Cleavage of PARP protein was most evident for NB1 cell line. Gapdh was used as protein loading control. D = DMSO. 
To further confirm that the autophagy was induced in SH-SY5Y cells after addition of entrectinib, we performed a transient transfection with GFP-LC3 plasmid. Under the fluorescence microscope, GFPLC3-transfected cells treated with DMSO showed a diffuse distribution of green fluorescence, whereas

A)
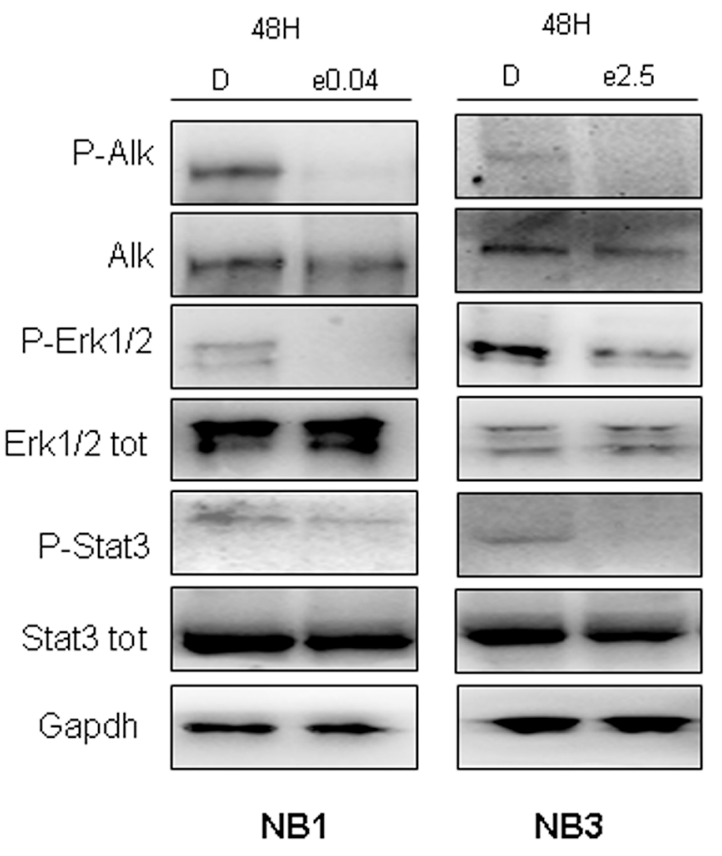

B)
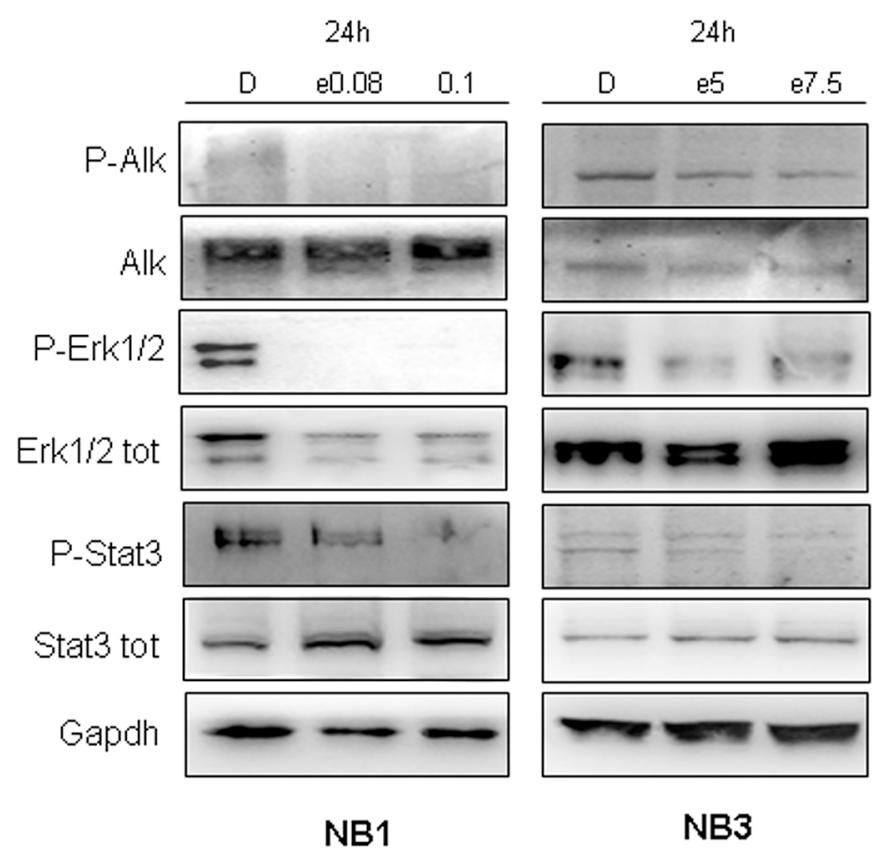

entrectinib treatment $(5 \mu \mathrm{M})$ triggered vesicle formation, creating a punctuated form of GFP-LC3 protein (Figure 6C). The diverse patterns confirmed that LC3 was engaged in autophagosome formation in entrectinib-induced autophagy in SH-SY5Y $\mathrm{F}^{\mathrm{F} 174 \mathrm{~L}}$ cell line.
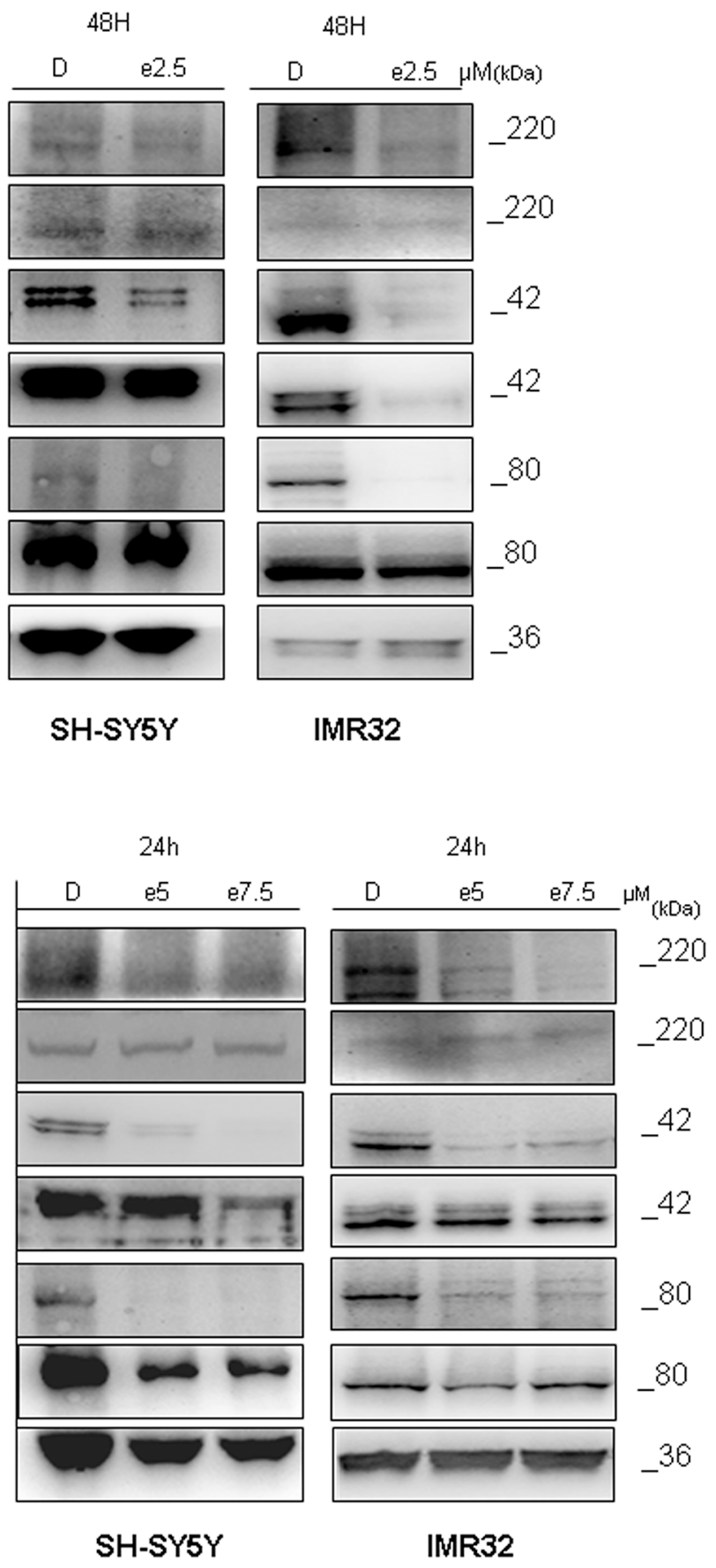

Figure 5: Entrectinib impacts ALK downstream protein pathway. Eventual change of ALK downstream pathway after treatment with entrectinib was validated by Western blot. Two different analyses were done: $\mathbf{A}$. using entrectinib (e) $\mathrm{IC}_{50}$ defined for $48 \mathrm{~h}$, and $\mathbf{B}$. using increasing concentration of entrectinib for $24 \mathrm{~h}$. Decreased activity of two principal downstream target of ALK protein, ERK1/2, and STAT3 can be seen by their reduced phosphorylation in either of immunoblots presented. Gapdh was used as a control of proper protein loading. Numbers beside letter (e) indicate concentration of entrectinib $(\mu \mathrm{M})$ used. D = DMSO. 
A)

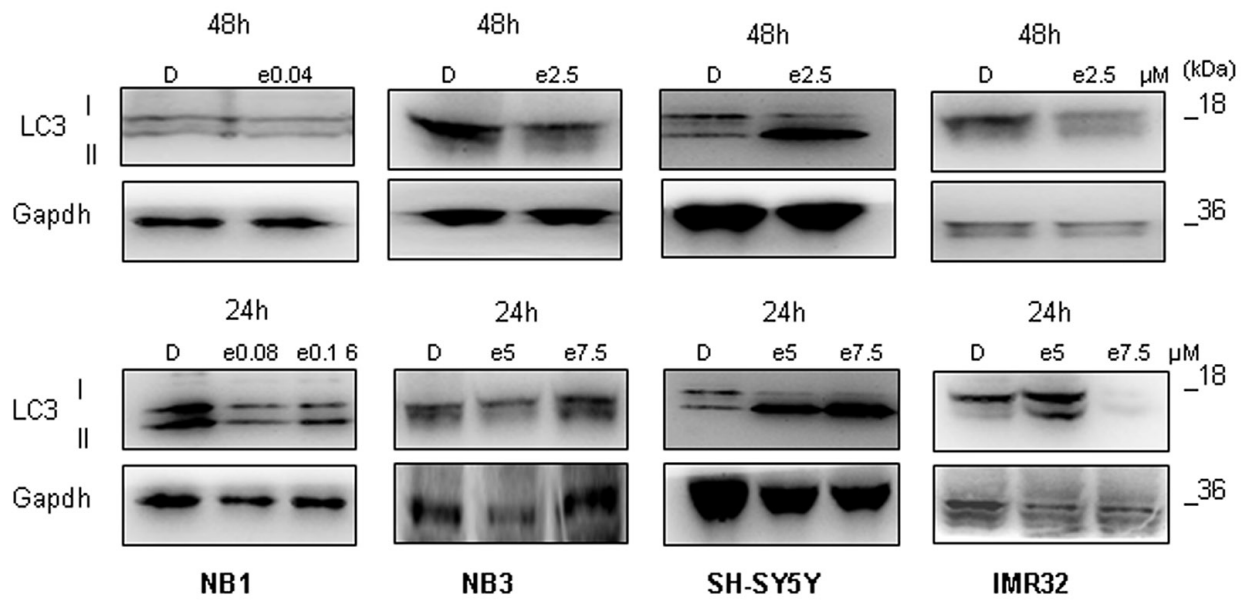

B)

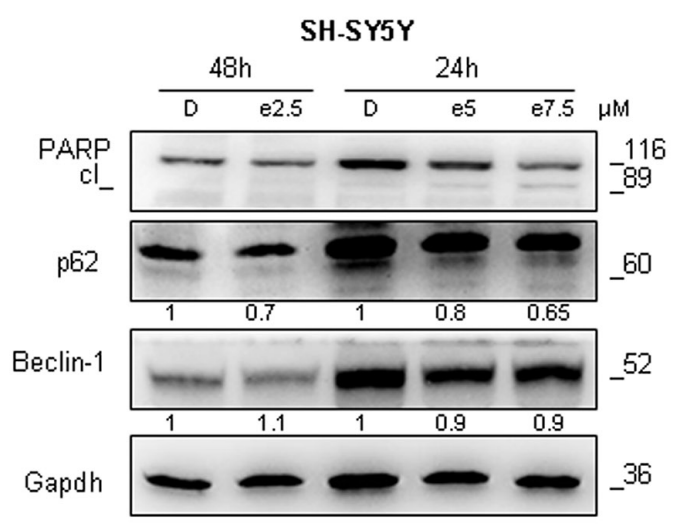

C)

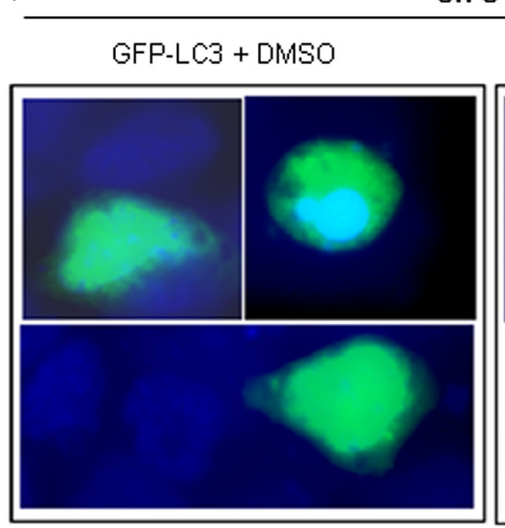

SH-SY5Y

GFP-LC3 + entrectinib

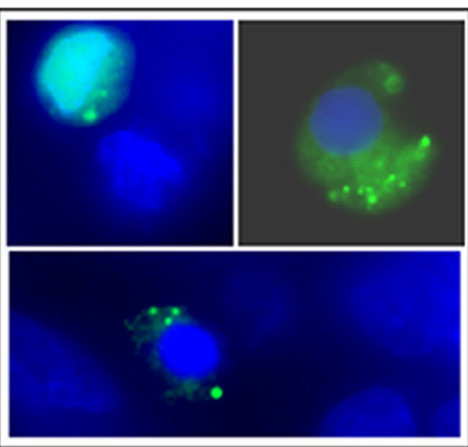

D)

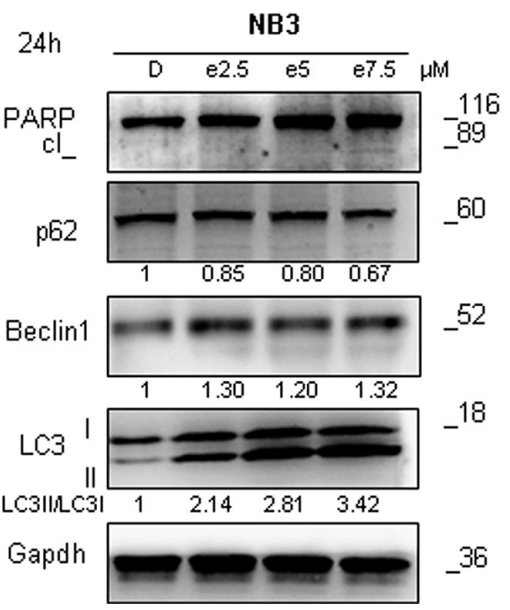

Figure 6: Entrectinib causes autophagy activation in ALK mutated NB cells. A. Immunoblot analyses of LC3 after treatment with $\mathrm{IC}_{50}$ (upper lane) or increasing concentration (lower lane) of entrectinib are presented. A significant processing of LC3 was seen for SH-SY5Y cells with $A L K^{\mathrm{F} 1174 \mathrm{~L}}$ mutation. Gapdh was used as a protein loading control. B. Apoptosis (PARP), and autophagy (p62, and Beclin-1) related proteins were examined in SH-SY5Y cell line for several concentrations of entrectinib (e), and for 2 time points, 24h and 48h. Gapdh was used as a control of proper protein loading. Numbers beside letter (e) indicate concentration of entrectinib $(\mu \mathrm{M})$ used in the experiments. Numbers alone indicate relative expression of the protein calculated by densitometry. D = DMSO. C. SH-SY5Y cells were transiently transfected with GFP-LC3 plasmid, and treated with entrectinib $(5 \mu \mathrm{M})$ or DMSO vehicle for $24 \mathrm{~h}$. Fluorescence microscopic analysis was done afterwards to evaluate a distribution of GFP-LC3 within the cells. Cell nuclei were counterstained with DAPI (blue). Images were taken on a confocal microscope (100X immersion objective), equipped with a digital camera. D. Apoptosis (PARP), and autophagy (LC3, p62, and Beclin-1) related proteins were examined in NB3 cell line for increasing concentration of entrectinib. Gapdh was used as a control of proper protein loading. Initial numbers indicate concentration of entrectinib (e) in $\mu \mathrm{M}$. Numbers under the blots indicate relative expression of the protein calculated by densitometry. $\mathrm{D}=\mathrm{DMSO}$. 


\section{Autophagy induction after entrectinib treatment was less obvious in NB3 cell line}

Our data demonstrate that the NB3 ${ }^{\mathrm{R} 1275 \mathrm{Q}}$ cells are slightly more sensitive to entrectinib than SH-SY5Y $Y^{\mathrm{F} 1174 \mathrm{~L}}$. To examine how different $A L K$ mutations may affect induction of autophagy in response to entrectinib, we checked the expression of principal autophagy regulators in NB3 cells $24 \mathrm{~h}$ post-treatment. Even in this cell line we could observe autophagy activation, although it was less marked in comparison to SH-SY5Y cells (Figure $6 \mathrm{D})$. Beside decrease in $\mathrm{p} 62$ protein levels, increase in LC3-II/LC3-I ratio (LC3-II/LC3-I ratio: DMSO = 1 AU; entrectinib $2.5 \mu \mathrm{M}=2.14 \mathrm{AU}$; entrectinib $5 \mu \mathrm{M}=2.81$ $\mathrm{AU}$; entrectinib $7.5 \mu \mathrm{M}=3.42 \mathrm{AU}$ ), and marginal cleavage of PARP protein, we confirmed a slight up-regulation of Beclin-1 protein for NB3 cell line (Figure 6D). These results indicated that autophagy induction followed a different pattern in diverse NB cell lines, but contributed directly to the sensitivity of NB cells to entrectinib.

\section{Inhibition of autophagy potentiates entrectinib- stimulated cell death}

To examine autophagic flux in SH-SY5Y $\mathrm{Y}^{\mathrm{F} 1174 \mathrm{~L}}$ cell line, we analyzed LC3-II in the presence of the lysosomal protease inhibitor chloroquine (CQ) [23]. We pre-treated SH-SY5Y cells with CQ $(50 \mu \mathrm{M}$; for $1 \mathrm{~h})$, and subsequently added entrectinib $(5 \mu \mathrm{M})$ to operate for 24h. Afterwards, proteins were extracted for Western blot analysis, while cell death was measured by flow cytometry (TUNEL assay). The dynamic autophagic process was confirmed after inhibition of lysosomal protease by CQ, through a notable accumulation of LC3-II, p62, and Beclin-1 proteins (Figure 7A). In addition, LC3II levels increased further in CQ-entrectinib co-treated cells compared to control. These findings implied that the observed accumulation of autophagic vacuoles resulted from autophagy induction rather than from their decreased degradation by lysosomes [24]. More importantly, the effects of CQ, in CQ+entrectinib combined treatment, provoked an increase in cell death, as confirmed by both, Western blot (PARP activation, Figure 7A) analysis or TUNEL assay $(\mathrm{DMSO}=5.8 \pm 1.0 ; \mathrm{CQ}=29.4 \pm 7.1$; entrectinib $=27.0 \pm 9.8 ; \mathrm{CQ}+$ entrectinib $=68.8 \pm 3.9 ; n=$ 3 ; $\mathrm{p}<0.05$; Figure $7 \mathrm{~B}$ ).

To explore whether the protective role of autophagy against entrectinib-induced cell death was cell specific, we chemically stimulated autophagy in NB1 cells by Tamoxifen ( $\mathrm{T}$ ), and Rapamycin (Ra), two well-known autophagic stimulators. After pre-treatment with $\mathrm{T}$ and $\mathrm{Ra}$, cells were treated with entrectinib, and LC3-II, and p62 levels were examined after 24h. Even though both compounds showed a capacity to increase LC 3 cleavage (LC3-I), and modification (LC3-II), the final effects were somewhat different (Figure 7C). In particular,
Tam lead to an increase of p62 levels, which drastically diminished in combination with entrectinib, implying for an enforcement of autophagic flux (Figure 7C, lane 3 and 4). Treatment with Rapa did not change p62, and LC3 levels, but did increase a cleavage of PARP protein when used in combination with entrectinib, suggesting for enforced apoptosis activation. These results suggested that NB1 cells survival was highly dependent on ALK activity, which may be considered as the main pathway that gave them the proliferative benefits. This also indicates that entrectinib affects autophagic flux, most probably at LC3-II level by sequestration into autophagosome. The opposite experiment performed on SH-SY5Y cells, using other autophagy inhibitors which are known to act upstream of phagophore formation (e.g. PI3K inhibitor LY294002 (Ly), and 3-Methyladenine (3MA)) supported these findings. Once again, entrectinib caused mild effects over cell death (PARP protein cleavage) when used alone in SH-SY5Y cells, but caused the important expressional changes of autophagy proteins LC3, and p62 (Figure 7D, lane 2 versus lane 1). Inhibition of autophagy after combination of entrectinib with LY294002, or 3-MA, was confirmed particularly at the level of p62 protein (Figure 7D, lane 4 and 6 versus lane 2) even though entrectinib maintained its capacity to induce stimulation of LC3-II. In addition, we also revealed the changes in the mTOR-regulating signaling pathway during autophagy activation (Supplementary Figure S4), which suggested that it might be involved in the regulation of this biological process as well. Taken together, these results confirmed a key role of autophagy in helping NB mutated cells to evade apoptosis in the presence of entrectinib, and suggested for the combined treatment of ALK- and autophagic-inhibitors in treatment of NB cells bearing $A L K$ gene mutation.

\section{Autophagy activation is an early event in SH- SY5Y}

Additionally, to define timing of autophagy activation after entrectinib administration, we treated SH-SY5Y cells for $6 \mathrm{~h}(5 \mu \mathrm{M})$, and analyzed LC3 protein expression afterwards. We could confirm that a protective mechanism in SH-SY5Y cells was activated rapidly in the presence of entrectinib, since LC3-II increased significantly even at this early time point. Autophagy was not observed in NB1 cell line after entrectinib treatment, which was in concordance with other results seen previously for this cell line. On the contrary, NB1 cells were highly sensitive to ALK inhibition attained by entrectinib. We could see that the kinetic of entrectinib in inducing NB1 cell death was quick as well, since $6 \mathrm{~h}$ treatment provoked a marked PARP cleavage (Figure 8). These findings imply that NB1 are ALK-addicted cells, in which ALK pathway obstruction provokes a destructive cell survival effect. 


\section{Crizotinib causes different autophagy-defined pattern in NB cells with respect to entrectinib, and marginal apoptosis activation}

Crizotinib, as a well known anti-ALK drug (PF02341066) was used for the treatment of some tumors, such as a non-small-cell lung cancer with $A L K$ rearrangements [25]. However, it was seen that crizotinib can induce autophagy in lung cancer cells, which

A)

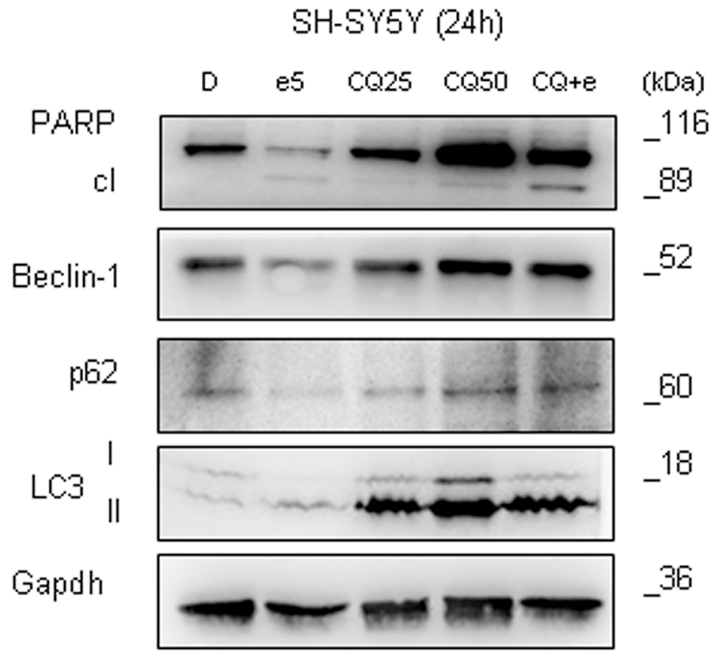

C)
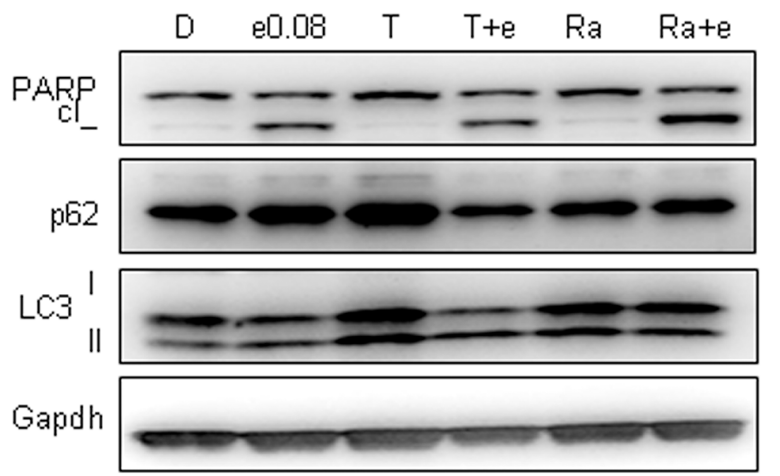

NB1

B)

D)

correlated with resistance to this drug [26]. To define whether crizotinib could provoke autophagy induction in ALK-mutated NB cells, we treated these cells with increasing concentration of crizotinib. After defining $\mathrm{IC}_{50}$ (Supplementary Table S6), we selected several concentration under, and above $\mathrm{IC}_{50}$ value, treated the cells, and controlled the expression of autophagy related proteins. Among $A L K$-mutated cell lines used for this experiment (NB3 and SH-SY5Y), autophagy induction
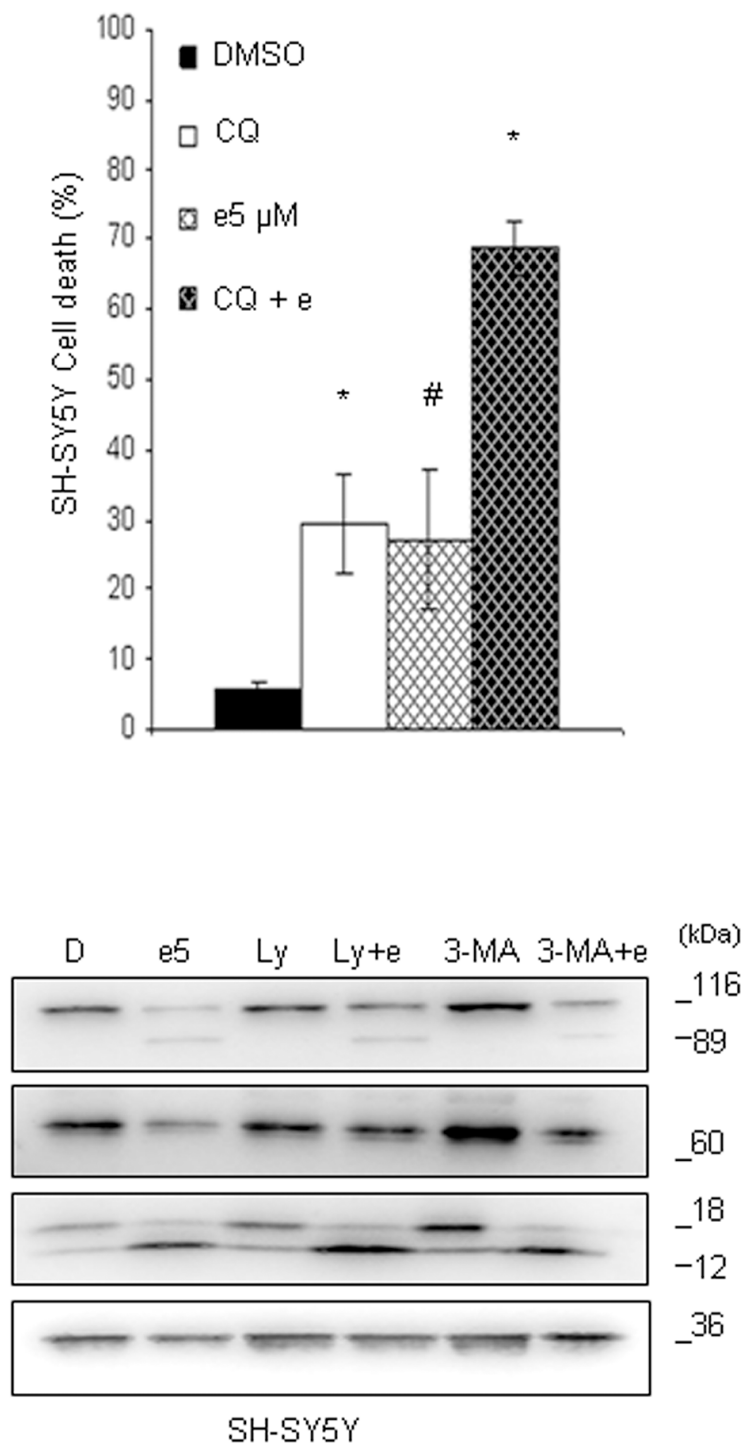

Figure 7: Entrectinib activity in SH-SY5Y cells increases after abrogation of autophagy. A. Cells were pre-incubated with Chloroquine (CQ; 25 and $50 \mu \mathrm{M}$ ) for $1 \mathrm{~h}$, and entrectinib $(\mathrm{e} ; 5 \mu \mathrm{M})$ was added in following for $24 \mathrm{~h}$. Whole cell lysates were used to evaluate the expression of PARP, p62, Beclin-1, and LC3 proteins for single or combined treatments. Gapdh was utilized as loading control. Numbers indicate concentration of compounds in $\mu \mathrm{M}$ used in the experiment. $\mathrm{D}=$ DMSO. B. Percentage of dead cells was measured by TUNEL assay, applying flow cytometry technique. The potential of entrectinib (e; $5 \mu \mathrm{M})$ to impair cell viability alone, or after pre-treatment with CQ $(50 \mu \mathrm{M})$, was confirmed in SH-SY5Y cell line. The effects of treatments, and DMSO control samples are presented as mean $\pm \mathrm{SEM}$. Results were considered significant for ${ }^{*} \mathrm{p} \leq 0.05$. $\# p=0.09$. C. Tamoxifen $(5 \mu \mathrm{M})$ and Rapamycin $(10 \mu \mathrm{M})$ were used to stimulate autophagy in NB1 cells, whereas D) LY294002 $(10 \mu \mathrm{M})$, and 3-MA $(50 \mu \mathrm{M})$ were used as autophagy inhibitors in SH-SY5Y cells. Immunoblot analyses were performed to verify the levels of apoptosis- and autophagy-related proteins. Gapdh served as a loading control. Abbreviations: D, DMSO; e, entrectinib; T, Tamoxifen; Ra, Rapamycin; Ly, Ly294002; 3-MA, 3-Methyladenine. Numbers indicate concentration of entrectinib ( $\mu \mathrm{M})$ used for the experiments. 
was more evident for the SH-SY5Y cells (Figure 9). In these cells we observed the increase in LC3-II/LC3-I ratio (LC3-II/LC3-I ratio: $\mathrm{DMSO}=1 \mathrm{AU}$; crizotinib $0.6 \mu \mathrm{M}=$ 1.36 AU; crizotinib $1.25 \mu \mathrm{M}=1.48 \mathrm{AU}$; crizotinib $2.5 \mu \mathrm{M}$ $=1.45 \mathrm{AU}$; crizotinib $5 \mu \mathrm{M}=2.52 \mathrm{AU}$ ), slight increase in Beclin-1 level, and almost unchanged expression of p62 protein. In NB3 cell line, there was no significant activation of autophagy after treatment with crizotinib (Figure 9). In addition, similarly to entrectinib, cell lines bearing $A L K$ mutations demonstrated PARP cleavage only at the concentrations around defined $\mathrm{IC}_{50}$ and above, pointing out that they generally showed poor susceptibility to crizotinib.

\section{DISCUSSION}

Neuroblastoma represents an embryonic tumor which derives from over-proliferating primitive neuroblast cells of the sympathetic nervous system. The most of NB cases are diagnosed during childhood [27]. Around $15 \%$ of all childhood cancer deaths occur due to NB, which makes it a tumor with a great medical, and social impact $[28,29]$. Some of the main genes described in
NB, $M Y C N$, and $A L K$, have been identified as the major pathogenic markers of this malignancy [12]. Therefore, it is understandable why the use of drugs against these markers represents a base for targeted therapy in NB patients. Relatively high frequency of NB patients with deregulated ALK tyrosine kinase rationalizes the ALKtargeting approach, which has been adopted during the recent years $[17,30]$. Nonetheless, the ALK-inhibition is found to be a problematic issue due to a rapid resistance development.

Nowadays, the resistance to the kinase inhibitors became one of the most awkward concerns of the oncologists [31]. This is true for the majority of solid tumors, including NBs. In particular, the advanced-stage NB tumors have a high frequency of treatment resistance, urging for innovative, and less aggressive therapies to be defined. To date, several ALK inhibitors have been tested for their efficiency to impede the NB growth, each with different activity [32].

The present study assessed the capability of entrectinib, a novel ALK tyrosine kinase inhibitor, to interfere with cancer cell growth, and proliferation. We tested its influence over viability, and motility of NB cells

\section{Eh:}
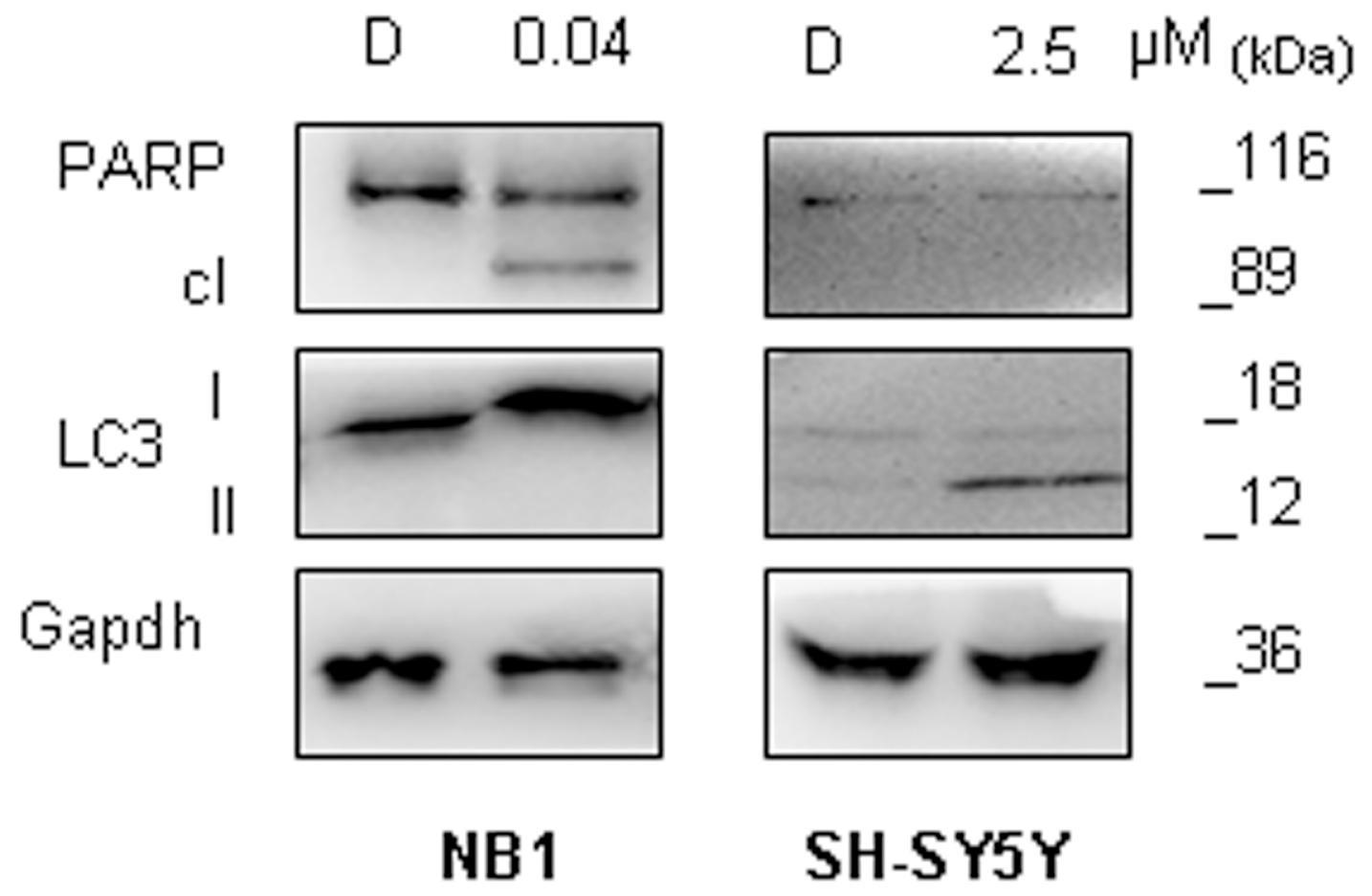

Figure 8: Autophagy activation is an early event in $A L K^{\text {F1174L }}$ mutated cells. A. Western blot analysis was done for the evaluation of LC3 processing, and hence, autophagy activation. NB1 and SH-SY5Y cells were treated shortly (6h) with entrectinib (e), using $0.04 \mu \mathrm{M}$, and $2.5 \mu \mathrm{M}$, respectively, and in following the expression of LC3-I, and LC3-II proteins was validated. We could confirm autophagy to be an early protective event in SH-SY5 $\mathrm{Y}^{\mathrm{F} 1174 \mathrm{~L}}$ cells, being activated after only $6 \mathrm{~h}$ of treatment with entrectinib. On the contrary, in NB1 ${ }^{\text {amp }}$ cells, entrectinib showed an immediate apoptosis activation, as confirmed by cleavage of PARP protein, which has not been observed for SH-SY5Y cells. Gapdh was used as protein loading control. D = DMSO. 


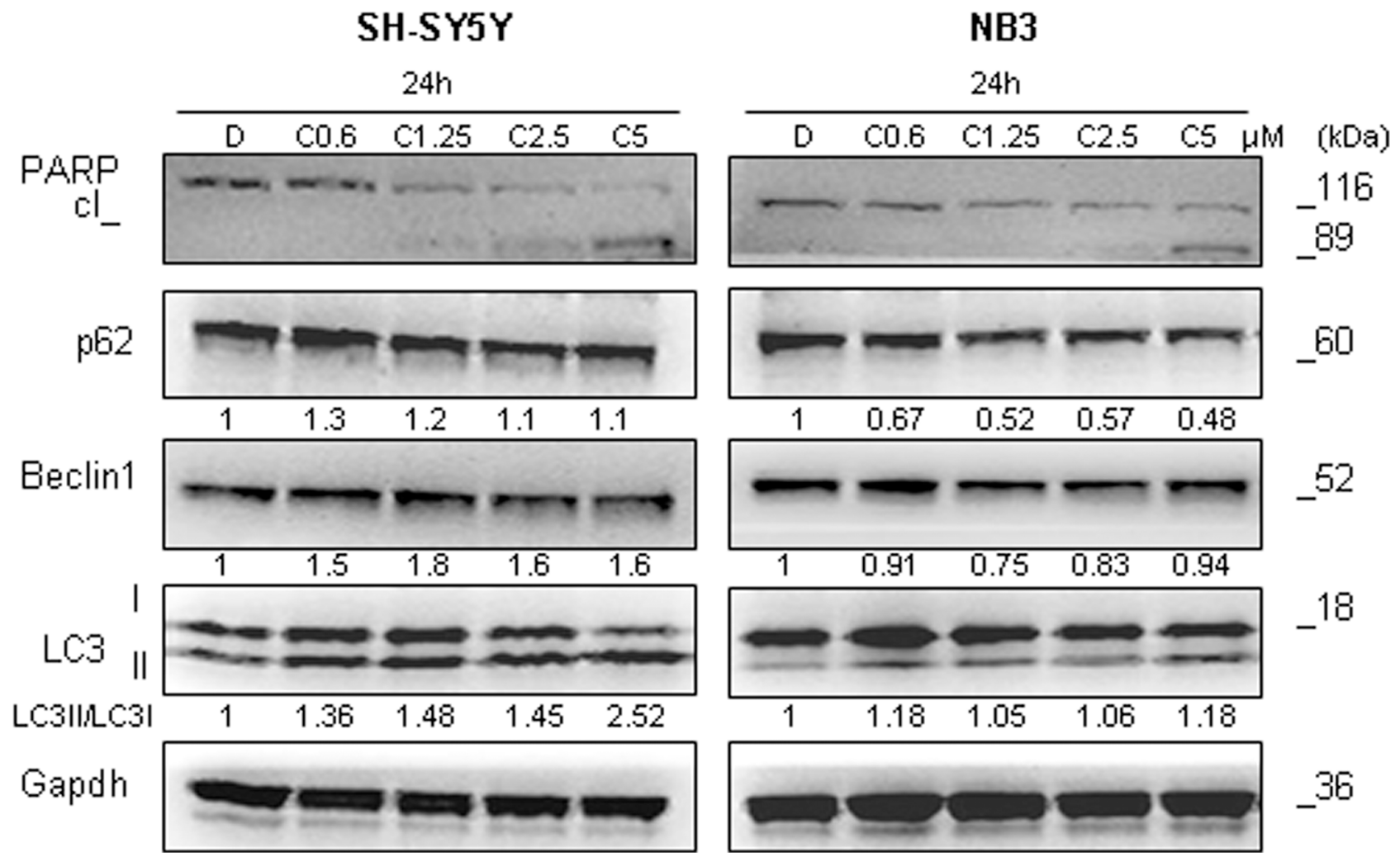

Figure 9: Effects of crizotinib on autophagy induction. Immunoblot analyses of autophagy (LC3, p62, and Beclin-1), and apoptosis (PARP) related proteins' expression after treatment with crizotinib are shown. Several concentrations of drug have been applied. Gapdh was used as a control of proper protein loading. Numbers beside letter (c) indicate concentration of crizotinib ( $\mu \mathrm{M})$ used in the experiments. Numbers under the blots indicate relative expression of the protein calculated by densitometry. D = DMSO.

with various mutation status of $A L K$ gene, and validated entrectinib-dependent cell death mediation in vitro.

We confirmed that the administration of entrectinib impaired cell proliferation, and abrogated cell-cycle progression, causing the G1-arrest. The rate of cellcycle blockage after the treatment was concomitant with diminished expression of the $K i-67$, and with the changes in the expression of the genes involved in cellcycle regulation. Nevertheless, we delineated a different amplitude of behavior to drug treatment between the ALK amplified or ALK mutated cells, confirming the results discussed by other groups [33]. The results obtained after treatment with entrectinib allowed us to determine that the NB1 cell line was strongly addicted to ALK activity, whereas ALK-mutation bearing cells were less ALK-dependent. In detail, we confirmed the impairment of ALK-downstream signaling molecules, such as pSTAT3, and pERK1/2, in the presence of entrectinib in all cell lines. As a consequence, proliferation of NB cells was impaired, and colony formation capacity was drastically decreased with respect to control treated samples. Also, the motility of the NB cells was significantly inhibited upon addition of entrectinib. However, described cytostatic effects of entrectinib were delineated with diverse intensity among examined NB cell lines.
Furthermore, our data indicated that entrectinib induced Caspase-3 dependent cell death, showing a dose-dependent effect in NB cells. At the protein level, cell mortality induction was confirmed in varying degree between $A L K$-amplified, mutated, or wild-type gene, by studying PARP protein cleavage.

Particular interest in our study was given to understand why the entrectinib efficacy was drastically lower in ALK-mutation bearing cells. We delineated that the mutation occurrence decreased the cell susceptibility to entrectinib through autophagy induction. Treatment of SHSY5Y ${ }^{\mathrm{F} 1174 \mathrm{~L}}$ cells with entrectinib resulted in the increased expression of LC3-II, and decreased level of p62 protein, both in time- and dosage-dependent manner. Autophagy was also morphologically characterized by evaluating the autophagosome formation in GFP-LC3 transfected SHSY5Y cells.

In trying to overcome the observed resistance, and improving the efficiency of entrectinib in these cells, we adopted the combination strategy, using entrectinib together with autophagy inhibitor, Chloroquine (CQ). This treatment rendered the tumor cells prone to death, translating the protective role of autophagy toward apoptosis induction, as confirmed by PARP cleavage, and increased percentage of dead cells in treated samples. These observations allow us to postulate for the existence 
of alternative signaling pathways which activation might influence a therapy response in NB patients. In various cancers, proteins from the phosphatidylinositol 3-kinase (PI3K)/AKT/mTOR signaling pathway are found altered [33], and have been correlated with autophagy regulation. In our study, we could also confirm the modulation of the mTOR-dependent pathway in SH-SY5Y cells' after entrectinib administration. More precisely, we confirmed that the co-treatment of entrectinib, and Rapamycin, a well-known mTOR inhibitor, was a good strategy to further improve the effects of ALK-inhibitor in NB1 cells. These data support the findings of Moore et al., obtained during examination of crizotinib efficiency in NB [34]. As crizotinib, entrectinib is also a promising ALK inhibitor, and both of drugs are currently in clinical trials for ALK-driven tumors (NCT01154140, and STARTRK-1, respectively). Although both drugs are potent inhibitors of wild-type ALK and ALK fusions, entrectinib is able to inhibit certain ALK mutants that are otherwise resistant to crizotinib [35]. The different sensitivity is likely due to differences in the exact positioning, and bonding of the inhibitor-target interaction between these two compounds (manuscript in preparation). In addition, unlike crizotinib, entrectinib is able to efficiently cross the blood-brain barrier therefore targeting brain tumors and brain metastases [36].

In conclusion, entrectinib inhibited NB cell proliferation, induced cell death, and caused cell cycle arrest, influencing largely the ALK downstream signaling pathway. Our findings identifies entrectinib as a potent inhibitor of ALK-amplified NB1 cells, which seem to be highly dependent on ALK activity, implying for ALK-addiction [37]. On the other side, a low efficiency in ALK-mutated NB cells was supported by the autophagy activation, which was successfully abrogated by combination therapy. In particular, we propose cotreatment of ALK-inhibitor, and CQ, as an effective approach in managing drug resistance, and likely recurrence, or metastasis of NB tumors. The combined treatment strategy may be critical for the increased clinical efficacy of anti-ALK drugs. Our data are in a good agreement with those of Zhang et al and Mitou et al, since they confirm a protective role of autophagy in ALK-dependent tumors other than NB, after use of ALKinhibitors [26, 38]. Altogether, our data suggest that the pharmacological inhibition of autophagy may be a valuable approach to combat acquired resistance to ALKtyrosine kinase inhibitor entrectinib, which we propose for a clinical evaluation in NB patients.

\section{MATERIALS AND METHODS}

\section{Cell culture and treatments}

Human NB tumor cell lines NB1, NB3, SH-SY5Y, and IMR32, kindly provided by Dr Luca Longo, from
IRCCS AOU San Martino - IST, Genoa, Italy, were cultured in RPMI-1640 medium (Sigma-Aldrich, Milan, Italy) with addition of antibiotics (1\%), and fetal bovine serum (FBS; 10\%; Gibco, Life Technologies, Monza, Italy). DNA typing for the cell line authentication was done prior the analyses. For each experiment, equal numbers of cells were seeded, and the concentration of DMSO equivalent to those of the chemicals used, was applied to control cells. Entrectinib was provided by Ignyta Inc. (San Diego, CA) under a material transfer agreement; Chloroquine (CQ), 3-Methyladenine (3MA), Tamoxifen (Tam), Rapamycin (Rapa), Ly294002 (Ly), and bovine serum albumin (BSA) were purchased from Sigma-Aldrich, crizotinib from Selleck Chemicals (Munich, Germany). The concentrations of the compounds used in the study were adapted for each experiment before use.

\section{Measurement of cell proliferation, viability and mortality}

Log-phase cells were seeded into the 96-wells plate (15.000 cells/well), and were allowed for the attachment overnight followed by the treatment with entrectinib (0-10 $\mathrm{MM})$ for $24 \mathrm{~h}, 48 \mathrm{~h}$ and $72 \mathrm{~h}$. Cellular proliferation was quantified with colorimetric methods based on the metabolic reduction of the soluble yellow MTT (3(4, 5-dimethylthiazol-2-yl)-2, 5-diphenyltetrazolium bromide) dye to its insoluble formazan [39]. Absorbance was red by VICTOR ${ }^{\mathrm{TM}}$ Multilabel Plate Reader (PerkinElmer, Waltham, MA) at $486 \mathrm{~nm}$. Results were normalized to time point zero $(\mathrm{T}=0 \mathrm{~h})$, and calculated for each treatment with respect to DMSO treated controls. Cell viability was determined by trypan blue exclusion assay plating $1 \times 10^{5}$ cells / well in 24 wells plate a day before treatment with entrectinib. The following day, for one randomly selected well, the starting cell number was calculated $(\mathrm{T}=0 \mathrm{~h})$, whereas to the remaining cells, increasing concentration of entrectinib was administered. Until the $3^{\text {rd }}$ day, every $24 \mathrm{~h}$ cell number was calculated after trypsinization, centrifugation, and re-suspension in $500 \mu \mathrm{l}$ of $1 \mathrm{xPBS}$. Staining was done with $0.5 \%$ trypan blue. The unstained cells were quantified using the Countess $^{\mathrm{TM}}$ automated cell counter (Invitrogen) and final data were calculated with respect to the number of cell determined at time point zero $(\mathrm{T}=0 \mathrm{~h})$, corresponding to the value 1 on the graph. Cell death was measured by flow cytometer Cytomics FC500 (Beckman Coulter, Brea, CA) using the Apodirect Kit (BD Bioscience, San Diego, CA). Fluorescein labeled TdT-mediated dUTP nick end labeling (TUNEL) assay allowed distinction of dying NB cells after treatment with entrectinib. Apoptosis was measured by flow cytometry measuring activation of Caspase-3, one of the hallmarks of early apoptotic events. Preparation of the cells for analysis was done as suggested by manufacturer. 


\section{RNA isolation, quantitative real-time polymerase chain reaction, and reverse-transcription polymerase chain reaction}

Total cellular RNA was extracted by TRIzol reagent (Invitrogen, Life Technologies), as indicated by the manufacturer and the quality was controlled on Agilent 2100 Bioanalyzer (Agilent Technologies, Tokyo, Japan). One mg of total RNA was reversely transcribed using random hexamers, and the Superscript II (Invitrogen) according to the manufacturer's instructions. Gene expression was evaluated by quantitative PCR (qRT-PCR; Applied Biosystems 7900HT Fast Real Time PCR System) using SYBR Green PCR Master Mixture Reagents (Applied Biosystems, Forest City, CA). The primer sets are available upon request. Gapdh was used to normalize levels of mRNA for the relative quantification method of analysis. qRT-PCR reactions $(20 \mu \mathrm{L})$ were carried out as triplicate reactions, and final data were calculated from three separate experiments. Relative quantification analysis was done using the comparative ddCt method [40]. Experimental data were expressed as the mean \pm SEM of the $\mathrm{n}$-fold change from at least three independent experiments.

\section{Wound healing assay}

The total of $3 \times 10^{4}$ cells $(80 \%$ confluence) were plated within each of the two cell culture reservoirs separated by a $500 \mu \mathrm{m}$ thick silicone wall (IBIDI, Milano, Italy). Day after, the silicone insert was removed from the surface and treatments with entrectinib or DMSO vehicle were performed on four different human NB cell lines. The cells were allowed to grow for another 48-72h, and images were taken every $24 \mathrm{~h}$. Images were taken by Nikon Eclipse TS100 microscope (NiKon Eclipse TS 100, Southern Micro Instruments, Marietta, GA) with a Nikon Coolpix camera attached to the microscope. Wound healing was analyzed by MyWim software provided by IBIDI [41] for each time point. Data were presented as percentage of scratch area obtained for 3 separate measurements as mean \pm SEM.

\section{Western blot analysis}

Samples containing $100 \mu \mathrm{g}$ of total proteins (for ALK detection), or $50 \mu \mathrm{g}$ (for proteins other than ALK) were lysed with commercially available lysis buffer (Biosource International; Camarillo, CA), and analyzed with SDS-polyacrylamide gel electrophoresis (SDSPAGE) using precast gradient polyacrylamide gels (BioRad, Milano, Italy). Separated proteins were transferred onto PVDF membranes, by using a semidry transfer cell (BioRad, Trans-blot SD), and blocked with $5 \%$ BSA in $1 x P B S$ for $1 \mathrm{~h}$ at room temperature. The membranes were probed with monoclonal antibody, at a dilution suggested by the manufacturer, overnight at $4^{\circ} \mathrm{C}$. Following primary antibodies were used: anti-PARP, anti-ERK1/2, antipERK1/2, anti-STAT3, anti-pSTAT3, and anti-pALK
(Cell Signaling, Danvers, MA), anti-LC3, anti-Beclin-1, and anti-Gapdh, (Novus Biologicals, Littleton, CO), anti-p62/SQSTM1 (Abnova, Taipei City, Taiwan), antiALK (Abcam, Cambridge, UK).

In following, the membranes were incubated with a horseradish peroxidase-conjugated secondary antibody (Santa Cruz Biotechnology, Santa Cruz, CA) for $1 \mathrm{~h}$ at room temperature, and the immunoreactive bands were detected with chemiluminescence substrate kit (ECL advance; Amersham Pharmacia Biotec, Piscataway, NJ) under the Alliance imaging system (UVItec, Cambridge, UK). Re-probing of a blot with new primary antibodies was done after the stripping of antigen-antibody complex using a mild stripping solution $(0.2 \mathrm{M}$ glycine- $\mathrm{HCl}$, $\mathrm{pH} 2.2,0.1 \%$ SDS, $0.01 \%$ Tween-20) for $1 \mathrm{~h}$ at room temperature, followed by 3 washing with $1 x P B S$ with $0.1 \%$ Tween-20 (Sigma-Aldrich). The membranes were then blocked as described, and re-probed with primary, and secondary antibodies as described.

\section{Colony formation assay}

Two thousand cells of each NB cell type were seeded in a 24 wells plate using MethoCult semi-solid medium (Stemcell Technologies, Milan, Italy), with the addition of entrectinib (concentration adapted for each cell type) or control DMSO vehicle, and cells were left to grow for 2 weeks. Colonies (foci) were visualized after being stained with MTT for 4h. Pictures of the colonies were taken under light microscope, and total colony number was determined for each well by ImageJ software [42]. Three independent experiments were done for each cell type.

\section{Cell cycle analysis}

Analysis of cell cycle was done by flow cytometry. NB cells were seeded in 6 wells plate at an initial density of $8 \times 10^{5}$ cells per well. Cells were left to adhere before being treated with entrectinib. At the end of treatment (24h), the cells were harvested by trypsinization, washed, fixed after centrifugation in $2 \mathrm{ml}$ of $70 \%$ Ethanol and left at $-20^{\circ} \mathrm{C}$ until analysis. After DNA staining by Propidium iodide (Sigma-Aldrich) in addition of RNase (Qiagen, Milan, Italy) for $30 \mathrm{~min}$ at room temperature in the dark, the cell-cycles of the samples were measured on a FACScalibur cytometer (Becton-Dickinson, Franklin Lakes, NJ). Analysis was performed with the CellQuest software, and presented as percentage of the cells in each phase of cell-cycle (G1, S and G2/M).

\section{Immunofluorescence imaging}

Cells were fixed in cold $4 \%$ formaldehyde washed in 1x phosphate-buffered saline (PBS), and permeabilized in $0.1 \%$ Triton-X 100 (Sigma-Aldrich, diluted in PBS) for 10 min. After blocking with $5 \%$ BSA in PBS for 30 min, samples were washed thrice in 1xPBS and incubated 
with rabbit-polyclonal anti-Ki-67 primary antibody (DakoCytomation, Carpinteria, CA) at $4^{\circ} \mathrm{C}$ overnight. After washing in $1 \times P B S$, the incubation with Alexa Fluor 594-conjugated goat anti-rabbit immunoglobulin G (red; 1:2.000, Life technologies, Monza, Italy) was done. Cell nuclei were counterstained with 40, 6-diamidino-2phenylindole (DAPI; blue; 1:10.000; Sigma-Aldrich) diluted in 1xPBS for $15 \mathrm{~min}$. Stained cells were mounted in Vector Shield mounting medium (Vector Laboratories LTD, Peterborough, UK), and images were examined under a fluorescence microscope at 60X (Vico, Eclipse Ti80, Nikon, Tokyo) or 100X (Carl Zeiss Microscopy, Germany) objective lens magnification equipped with a digital camera. Laser power, optimized on control-stained cells, remained the same throughout each experiment.

\section{Transient transfections with GFP-LC3 plasmid}

Plasmid carrying a construct for a green fluorescent protein labeled to autophagosome-associated LC3 protein (GFP-LC3) was kindly provided by $\mathrm{Dr}$ Leonardo Salviati research group from the IRP- Città della Speranza, Padua, Italy. The SH-SY5Y cells were transiently transfected using Effectene Transfection Reagent (Qiagen) following manufacturer procedure, with $2-4 \mu \mathrm{g}$ of plasmid DNA in 24 wells plate. After $24 \mathrm{~h}$, entrectinib was added $(5 \mu \mathrm{M})$, and $24 \mathrm{~h}$ later immunocytochemistry was performed using DAPI to mark cells' nuclei. The localization of GFP-LC3 within SH-SY5Y transfected cells was determined by fluorescence microscopy.

\section{Statistical analyses}

All experiments were repeated independently at least three times, and the experimental data were expressed as the mean \pm SEM. Statistical analyses were conducted using Student's t-test. Group differences resulting in $p$ values of $\leq 0.05$ were considered to be statistically significant, and marked with the asterisk *p on the graphs. All analyses were carried out with the GraphPad Prism program (GraphPad Software, Inc., San Diego, CA). Error bars on all graphs consider $95 \%$ confidence intervals.

\section{ACKNOWLEDGMENTS}

The authors would like to thank to Fondazione Italiana alla Lotta al Neuroblastoma, who supported the realization of this project.

\section{CONFLICTS OF INTEREST} declare.

\section{Authors' contributions}

SA designed, and performed the study, analyzed the results, and wrote the manuscript. GPT assisted in designing of the experiments, and provided a conceptual advice. GPT, MRE, and GL revised the manuscript. MP, and AS gave technical support for the experimental setup. $\mathrm{CZ}$ helped with statistical analyses. All authors read, and approved the manuscript.

\section{REFERENCES}

1. SEER Program (National Cancer Institute (U.S.)) and National Cancer Institute (U.S.). 1999 Cancer incidence and survival among children and adolescents United States SEER Program, 1975-1995. Bethesda, Md.: National Cancer Institute.

2. Tonini GP, Nakagawara A, Berthold F. Towards a turning point of neuroblastoma therapy. Cancer Lett 2012; 326:128-134.

3. Maris JM. Recent advances in neuroblastoma. N Engl J Med 2010; 362:2202-2211.

4. Schwab M. MYCN in neuronal tumours. Cancer Lett 2004; 204:179-187.

5. Maris JM, Matthay KK. Molecular biology of neuroblastoma. J Clin Oncol 1999; 17:2264-2279.

6. Molenaar JJ, Koster J, Zwijnenburg DA, van Sluis P, Valentijn LJ, van der Ploeg I, Hamdi M, van Nes J, Westerman BA, van Arkel J, Ebus ME, Haneveld F, Lakeman A, et al. Sequencing of neuroblastoma identifies chromothripsis and defects in neuritogenesis genes. Nature 2012; 483:589-593.

7. Pugh TJ, Morozova O, Attiyeh EF, Asgharzadeh S, Wei JS, Auclair D, Carter SL, Cibulskis K, Hanna M, Kiezun A, Kim J, Lawrence MS, Lichenstein L, et al. The genetic landscape of high-risk neuroblastoma. Nat Genet 2013; 45:279-284.

8. Carén H, Abel F, Kogner P, Martinsson T. High incidence of DNA mutations and gene amplifications of the ALK gene in advanced sporadic neuroblastoma tumours. Biochem J 2008; 416:153-159.

9. Iwahara T, Fujimoto J, Wen D, Cupples R, Bucay N, Arakawa T, Mori S, Ratzkin B, Yamamoto T. Molecular characterization of ALK, a receptor tyrosine kinase expressed specifically in the nervous system. Oncogene 1997; 14:439-449.

10. Berry T, Luther W, Bhatnagar N, Jamin Y, Poon E, Sanda T, Pei D, Sharma B, Vetharoy WR, Hallsworth A, Ahmad Z, Barker K, Moreau L, et al. The ALK(F1174L) Mutation Potentiates the Oncogenic Activity of MYCN in Neuroblastoma. Cancer Cell 2012; 22:117-130.

11. Passoni L, Longo L, Collini P, Coluccia AM, Bozzi F, Podda M, Gregorio A, Gambini C, Garaventa A, Pistoia V, Grosso F, Tonini GP, Cheng M, et al. Mutationindependent anaplastic lymphoma kinase overexpression in 
poor prognosis neuroblastoma patients. Cancer Res 2009; 69:7338-7346.

12. George RE, Sanda T, Hanna M, Frohling S, Luther W, 2nd, Zhang J, Ahn Y, Zhou W, London WB, McGrady P, Xue L, Zozulya S, Gregor VE, et al. Activating mutations in ALK provide a therapeutic target in neuroblastoma. Nature 2008; 455:975-978.

13. Mossé YP, Lim MS, Voss SD, Wilner K, Ruffner K, Laliberte J, Rolland D, Balis FM, Maris JM, Weigel BJ, Ingle AM, Ahern C, Adamson PC, Blaney SM. Safety and activity of crizotinib for paediatric patients with refractory solid tumours or anaplastic large-cell lymphoma: a Children's Oncology Group phase 1 consortium study. Lancet Oncol 2013; 14:472-480.

14. Sakamoto H, Tsukaguchi T, Hiroshima S, Kodama T, Kobayashi T, Fukami TA, Oikawa N, Tsukuda T, Ishii N, Aoki Y. CH5424802, a selective ALK inhibitor capable of blocking the resistant gatekeeper mutant. Cancer Cell 2011; 19:679-690.

15. Lambertz I, Kumps C, Claeys S, Lindner S, Beckers A, Janssens E, Carter DR, Cazes A, Cheung BB, De Mariano M, De Bondt A, De Brouwer S, Delattre O et al. Upregulation of MAPK Negative Feedback Regulators and RET in Mutant ALK Neuroblastoma: Implications for Targeted Treatment. Clin Cancer Res 2015; 21:3327-3339.

16. Schlüter C, Duchrow M, Wohlenberg C,. Becker MH, Key G, Flad HD, Gerdes J. The cell proliferation-associated antigen of antibody Ki-67: a very large, ubiquitous nuclear protein with numerous repeated elements, representing a new kind of cell cycle-maintaining proteins J Cell Biol 1993; 123:513-522.

17. Janoueix-Lerosey I, Lequin D, Brugieres L, Ribeiro A, Pontual L, Combaret V, Raynal V, Puisieux A, Schleiermacher G, Pierron G, Valteau-Couanet D, Frebourg $\mathrm{T}$, Michon J, et al. Somatic and germline activating mutations of the ALK kinase receptor in neuroblastoma. Nature 2008; 455:967-970.

18. Shen HM, Codogno P: Autophagic cell death: Loch Ness monster or endangered species? Autophagy 2011; 7:457-465.

19. Kabeya Y, Mizushima N, Ueno T, Yamamoto A, Kirisako T, Noda T, Kominami E, Ohsumi Y, Yoshimori T. LC3, a mammalian homologue of yeast Apg8p, is localized in autophagosome membranes after processing. Embo J 2000; 19:5720-5728.

20. Klionsky DJ, Abeliovich H, Agostinis P, Agrawal DK, Aliev G, Askew DS, Baba M, Baehrecke EH, Bahr BA, Ballabio A, Bamber BA, Bassham DC, Bergamini E, et al Guidelines for the use and interpretation of assays for monitoring autophagy in higher eukaryotes. Autophagy 2008; 4:151-175.
21. Bjorkoy G, Lamark T, Johansen T. p62/SQSTM1: a missing link between protein aggregates and the autophagy machinery. Autophagy 2006; 2: 138-139.

22. McCoy F, Hurwitz J, McTavish N, Paul I, Barnes C, O’Hagan B, Odrzywol K, Murray J, Longley D, McKerr G, Fennell DA. Obatoclax induces Atg7-dependent autophagy independent of beclin-1 and BAX/BAK. Cell Death Dis 2010; 1:e108.

23. Shintani T, Klionsky DJ. Autophagy in Health and Disease: A Double-Edged Sword. Science 2004; 306:990-995.

24. Mizushima N, Yoshimori T, Levine B. Methods in mammalian autophagy research. Cell 2010; 140:313-326.

25. Kwak EL, Bang YJ, Camidge DR, Shaw AT, Solomon B, Maki RG, Ou SH, Dezube BJ, Jänne PA, Costa DB, Varella-Garcia M, Kim WH, Lynch TJ,.et al. Anaplastic lymphoma kinase inhibition in non-small-cell lung cancer. N Engl J Med 2010;363:1693-1703.

26. Zhang L, Cheng Y, Patel R, Wu H, Zhang Y, Wang M, Ji S, Belani CP, Yang JM, Ren X. Induction of autophagy contributes to crizotinib resistance in ALK-positive lung cancer. Cancer Biol Ther 2014; 15:570-577.

27. Brodeur GM. Neuroblastoma: biological insights into a clinical enigma. Nat Rev Cancer 2003; 3:203-216.

28. Park JR, Eggert A, Caron H. Neuroblastoma: biology, prognosis, and treatment. Hematol Oncol Clin North Am 2010; 24:65-86.

29. Tweddle DA, Pinkerton CR, Lewis IJ, Ellershaw C, Cole $\mathrm{M}$, Pearson AD. OPEC/OJEC for stage 4 neuroblastoma in children over 1 year of age. Med Pediatr Oncol 2001; 36:239-242.

30. Mossé YP, Laudenslager M, Longo L, Cole KA, Wood A, Attiyeh EF, Laquaglia MJ, Sennett R, Lynch JE, Perri P, Laureys G, Speleman F, Kim C, et al. Identification of ALK as a major familial neuroblastoma predisposition gene. Nature 2008; 455:930-935.

31. Kummar S, Chen HX, Wright J, Holbeck S, Millin MD, Tomaszewski J, Zweibel J, Collins J, Doroshow JH. Utilizing targeted cancer therapeutic agents in combination: novel approaches and urgent requirements. Nat Rev Drug Discov 2010; 9:843-856.

32. Cheung NK, Dyer MA. Neuroblastoma: developmental biology, cancer genomics and immunotherapy. Nat Rev Cancer 2013; 13:397-411.

33. Hennessy BT, Smith DL, Ram PT, Lu Y, Mills GB. Exploiting the PI3K/AKT pathway for cancer drug discovery. Nat Rev Drug Discov 2005; 4:988-1004.

34. Moore N, Azarova A, Bhatnagar N, Ross K, Drake L, Frumm S, Liu Q, Christie A, Sanda T, Chesler L, Kung A, Gray N, Stegmaier K, George R. Molecular rationale for the use of PI3K/AKT/mTOR pathway inhibitors in combination with crizotinib in ALK-mutated neuroblastoma. Oncotarget 2014; 5:8737-8749. doi: 10.18632/oncotarget.2372. 
35. Rolfo C, Ruiz R, Giovannetti E, Gil-Bazo I, Russo A, Passiglia F, Giallombardo M, Peeters M, Raez L. Entrectinib: a potent new TRK, ROS1, and ALK inhibitor, Expert Opinion on Investigational Drugs 2015; 24:11,1493-1500.

36. Costa DB, Kobayashi S, Pandya SS, Yeo WL, Shen Z, Tan W, Wilner KD. CSF concentration of the anaplastic lymphoma kinase inhibitor crizotinib. J Clin Oncol 2011; 29:e443-e445.

37. Weinstein IB, Joe A, Felsher D. Oncogene addiction. Cancer Res 2008; 68:3077-3080.

38. Mitou G, Frentzel J, Desquesnes A, Le Gonidec S, AlSaati T, Beau I, Lamant L, Meggetto F, Espinos E, Codogno P, Brousset P, Giuriato S. Targeting autophagy enhances the anti-tumoral action of crizotinib in ALK-positive anaplastic large cell lymphoma. Oncotarget 2015; 6:30149-30164. doi: 10.18632/oncotarget.4999

39. Twentyman PR, Fox NE, Rees JK. Chemosensitivity testing of fresh leukaemia cells using the MTT colorimetric assay. Br J Haematol. 1989; 71:19-24.

40. Livak KJ, Schmittgen TD. Analysis of relative gene expression data using real-time quantitative PCR and 2-ddCT method. Methods 2001; 25:402-408.

41. Gebäck T, Schulz MMP, Koumoutsakos P, Detmar M. A novel and simple software tool for automated analysis of monolayer wound healing assays. BioTechniques 2009; 46:265-274.

42. Schneider CA, Rasband WS, Eliceiri KW. NIH Image to ImageJ: 25 years of image analysis. Nature methods 2012; 9:671-675. 